\title{
Meta-analysis of relationships between enteric methane yield and milk fatty acid profile in dairy cattle
}

\author{
H. J. van Lingen, ${ }^{*} \dagger^{1}$ L. A. Crompton, $\ddagger$ W. H. Hendriks, $† \S$ C. K. Reynolds, $\ddagger$ and J. Dijkstra† \\ ${ }^{*}$ TI Food and Nutrition, PO Box 557, 6700 AN Wageningen, the Netherlands \\ †Animal Nutrition Group, Wageningen University, PO Box 338, 6700 AH Wageningen, the Netherlands \\ †Division of Food Production and Quality, School of Agriculture, Policy and Development, University of Reading, Reading RG6 6AR, \\ United Kingdom \\ §Faculty of Veterinary Medicine, Utrecht University, PO Box 80.163, 3508 TD Utrecht, the Netherlands
}

\begin{abstract}
Various studies have indicated a relationship between enteric methane $\left(\mathrm{CH}_{4}\right)$ production and milk fatty acid (FA) profiles of dairy cattle. However, the number of studies investigating such a relationship is limited and the direct relationships reported are mainly obtained by variation in $\mathrm{CH}_{4}$ production and milk FA concentration induced by dietary lipid supplements. The aim of this study was to perform a meta-analysis to quantify relationships between $\mathrm{CH}_{4}$ yield (per unit of feed and unit of milk) and milk FA profile in dairy cattle and to develop equations to predict $\mathrm{CH}_{4}$ yield based on milk FA profile of cows fed a wide variety of diets. Data from 8 experiments encompassing 30 different dietary treatments and 146 observations were included. Yield of $\mathrm{CH}_{4}$ measured in these experiments was $21.5 \pm 2.46$ $\mathrm{g} / \mathrm{kg}$ of dry matter intake (DMI) and $13.9 \pm 2.30 \mathrm{~g} /$ $\mathrm{kg}$ of fat- and protein-corrected milk (FPCM). Correlation coefficients were chosen as effect size of the relationship between $\mathrm{CH}_{4}$ yield and individual milk FA concentration (g/100 g of FA). Average true correlation coefficients were estimated by a random-effects model. Milk FA concentrations of C6:0, C8:0, C10:0, C16:0, and C16:0-iso were significantly or tended to be positively related to $\mathrm{CH}_{4}$ yield per unit of feed. Concentrations of trans- $6+7+8+9$ C18:1, trans- $10+11 \mathrm{C} 18: 1$, cis$11 \mathrm{C} 18: 1$, cis-12 C18:1, cis-13 C18:1, trans-16+cis-14 C18:1, and cis-9,12 C18:2 in milk fat were significantly or tended to be negatively related to $\mathrm{CH}_{4}$ yield per unit of feed. Milk FA concentrations of C10:0, C12:0, C14:0-iso, C14:0, cis-9 C14:1, C15:0, and C16:0 were significantly or tended to be positively related to $\mathrm{CH}_{4}$ yield per unit of milk. Concentrations of C4:0, C18:0, trans-10+11 C18:1, cis-9 C18:1, cis-11 C18:1, and cis9,12 C18:2 in milk fat were significantly or tended to be negatively related to $\mathrm{CH}_{4}$ yield per unit of milk. Mixed
\end{abstract}

Received April 22, 2014

Accepted July 30, 2014.

${ }^{1}$ Corresponding author: henk.vanlingen@wur.nl model multiple regression and a stepwise selection procedure of milk FA based on the Bayesian information criterion to predict $\mathrm{CH}_{4}$ yield with milk FA as input $(\mathrm{g} / 100 \mathrm{~g}$ of $\mathrm{FA})$ resulted in the following prediction equations: $\mathrm{CH}_{4}(\mathrm{~g} / \mathrm{kg}$ of DMI $)=23.39+9.74 \times \mathrm{C} 16: 0-$ iso $-1.06 \times$ trans $-10+11 \mathrm{C} 18: 1-1.75 \times$ cis- $9,12 \mathrm{C} 18: 2$ $\left(\mathrm{R}^{2}=0.54\right)$, and $\mathrm{CH}_{4}(\mathrm{~g} / \mathrm{kg}$ of $\mathrm{FPCM})=21.13-1.38$ $\times \mathrm{C} 4: 0+8.53 \times \mathrm{C} 16: 0-$ iso $-0.22 \times$ cis-9 $\mathrm{C} 18: 1-0.59$ $\times$ trans $-10+11 \mathrm{C} 18: 1\left(\mathrm{R}^{2}=0.47\right)$. This indicated that milk FA profile has a moderate potential for predicting $\mathrm{CH}_{4}$ yield per unit of feed and a slightly lower potential for predicting $\mathrm{CH}_{4}$ yield per unit of milk.

Key words: methane, milk fatty acid profile, metaanalysis, dairy cattle

\section{INTRODUCTION}

Enteric fermentation is the main source of greenhouse gas (GHG) emissions from dairy cattle, with enteric $\mathrm{CH}_{4}$ amounting to $1.1 \mathrm{Gt}$ per year, representing $46 \%$ of the total GHG emissions in dairy supply chains (Gerber et al., 2013). Enteric $\mathrm{CH}_{4}$ production is among the main targets of GHG mitigation practices for the dairy industry (Hristov et al., 2013). In view of these emissions and various mitigation options, there is a clear need for simple and inexpensive measurement techniques to estimate $\mathrm{CH}_{4}$ emissions from dairy cattle in commercial practice.

Various methods have been used to estimate $\mathrm{CH}_{4}$ production from ruminants. Production of $\mathrm{CH}_{4}$ can be measured in respiration chambers, which is an accurate but expensive technique, unsuitable for application on a large scale. Other methods, including the $\mathrm{SF}_{6}$ marker and $\mathrm{CH}_{4}: \mathrm{CO}_{2}$ ratio techniques, enable $\mathrm{CH}_{4}$ emissions to be determined in a larger number of animals but with higher between- and within-animal variation (Storm et al., 2012). For inventory and prediction purposes, many empirical equations have been developed to relate $\mathrm{CH}_{4}$ production per day or yield per unit of feed to feed intake and composition. Such equations have major limitations in predicting effects of mitigation strategies 
at the whole-farm level (Ellis et al., 2010). Mechanistic models describing the mechanism of enteric feed degradation provide more accurate predictions of $\mathrm{CH}_{4}$ production than do empirical models (Alemu et al., 2011). However, mechanistic models are more complex and require inputs that may not be commonly measured. In addition, forcing functions used and bias in parameter values adopted may limit the meticulousness of predicted model output. For these reasons, a simple and robust prediction equation of enteric $\mathrm{CH}_{4}$ yield from dairy cattle based on characteristics of feed or milk would be valuable for application on a large scale in GHG mitigation practices for the dairy industry.

Milk samples are frequently used in dairy farms to assess the nutritional and health status of dairy cattle and to obtain information on losses to the environment. For example, milk urea content is used to assess protein status of the animal and to estimate $\mathrm{N}$ excretion (Spek et al., 2013). Several studies have related diet composition to both milk FA composition and enteric $\mathrm{CH}_{4}$ production (e.g., Chilliard et al., 2009). Such relationships may be a result of lipid supplementation, which changes both $\mathrm{CH}_{4}$ production and milk FA profile, or may be a result of changes in diet composition, in view of $\mathrm{CH}_{4}$ production being associated with the VFA profile produced in the rumen (Ellis et al., 2008) and VFA in turn being precursors of milk FA synthesized de novo (Bernard et al., 2008). The odd- and branched-chain fatty acid (OBCFA) content of milk has also been shown to be related to rumen function (Vlaeminck et al., 2006a).

Chilliard et al. (2009) supplemented cattle diets with different physical forms of linseed (crude, extruded, and oil). The most positive correlations between $\mathrm{CH}_{4}$ production (g/d) and milk FA concentrations were obtained for saturated FA (C6:0 to C16:0) and the most negative correlations for various trans-C18 FA. Milk OBCFA concentrations exhibited less strong correlations with $\mathrm{CH}_{4}$ production. These relationships may only apply to linseed supplemented diets. Mohammed et al. (2011), using only dietary oilseed supplementation (sunflower seed, linseed, and canola seed), best predicted $\mathrm{CH}_{4}$ production (g/d) by milk FA concentration of C16:0-iso (positive relationship) and cis-9 C17:1 (negative relationship). Dijkstra et al. (2011), using a larger variety of diets (3 experiments, 10 dietary treatments) in which fat supplementation was a major source of dietary variation, evaluated relationships between $\mathrm{CH}_{4}$ yield per unit of feed and milk FA profile in dairy cattle. Their prediction equation included milk FA concentration of C17:0-anteiso and cis-13 C18:1 (positive relationship) and trans-10+11 C18:1 and cis-11 C18:1 (negative relationship). The various models to predict $\mathrm{CH}_{4}$ emission in these 3 studies have only a few milk FA in common. This might be a result of the small num- ber of experiments and the limited variation in dietary treatments as well as the analytical methods used to elucidate milk FA profile. Data from a greater number of experiments containing a wider variety of diets are required to firmly assess the potential of milk FA profile as an indicator of $\mathrm{CH}_{4}$ yield. A greater number of experiments also allows quantification of between-study variability or heterogeneity of the correlation between milk FA concentrations and $\mathrm{CH}_{4}$ yield.

The aims of this study were to perform a meta-analysis to quantify relationships between $\mathrm{CH}_{4}$ yield and individual milk FA concentrations in lactating dairy cattle while quantifying the heterogeneity of these relationships, and to develop equations to predict $\mathrm{CH}_{4}$ yield (per unit of feed and per unit of milk) based on milk FA profile of cows fed a wide variety of diets. Such equations may ultimately be used to estimate $\mathrm{CH}_{4}$ yield from dairy cattle under field conditions to fulfill the need for simple, inexpensive measurement techniques.

\section{MATERIALS AND METHODS}

\section{Data Collection}

For inclusion in the present meta-analysis, studies were required to have $\mathrm{CH}_{4}$ production measured using respiration chambers and milk FA profile elucidated using gas chromatography. Four studies designed as $4 \times 4$ Latin squares from the University of Reading (Reading, UK) and 4 studies designed as randomized block experiments from Wageningen University (Wageningen, the Netherlands) met these requirements and were included (Table 1). The procedures to determine $\mathrm{CH}_{4}$ production and milk FA profile are described by Kliem et al. (2008) and Reynolds et al. (2014) for the Reading studies and by van Knegsel et al. (2007) for the Wageningen studies. The 8 studies represented 30 different dietary treatments and 146 individual observations encompassing a variety of diets. Studies 1, 3, 4, 7 , and 8 contained lipid treatments, whereas studies 2 , 5 , and 6 did not contain any lipid treatment. Studies 4 and 5 comprised diet treatments with different forage types and contents, and studies 2, 6, 7, and 8 contained various nonlipid additives. Animals were described by treatment diet composition, DMI, milk yield, milk composition, milk FA profile, and $\mathrm{CH}_{4}$ production (Tables 2 and 3). Methane yield was expressed per unit of feed (g/ $\mathrm{kg}$ of DMI) and per unit of fat- and protein-corrected milk (g/kg of FPCM), where FPCM $(\mathrm{kg} / \mathrm{d})=[0.337$ $+0.116 \times$ milk fat $(\%)+0.06 \times$ milk protein $(\%)] \times$ milk production $(\mathrm{kg} / \mathrm{d})$ (CVB, 2008).

Some of the milk FA profile analyses did not allow identification of certain individual milk FA but did identify certain FA together as one fraction. When 


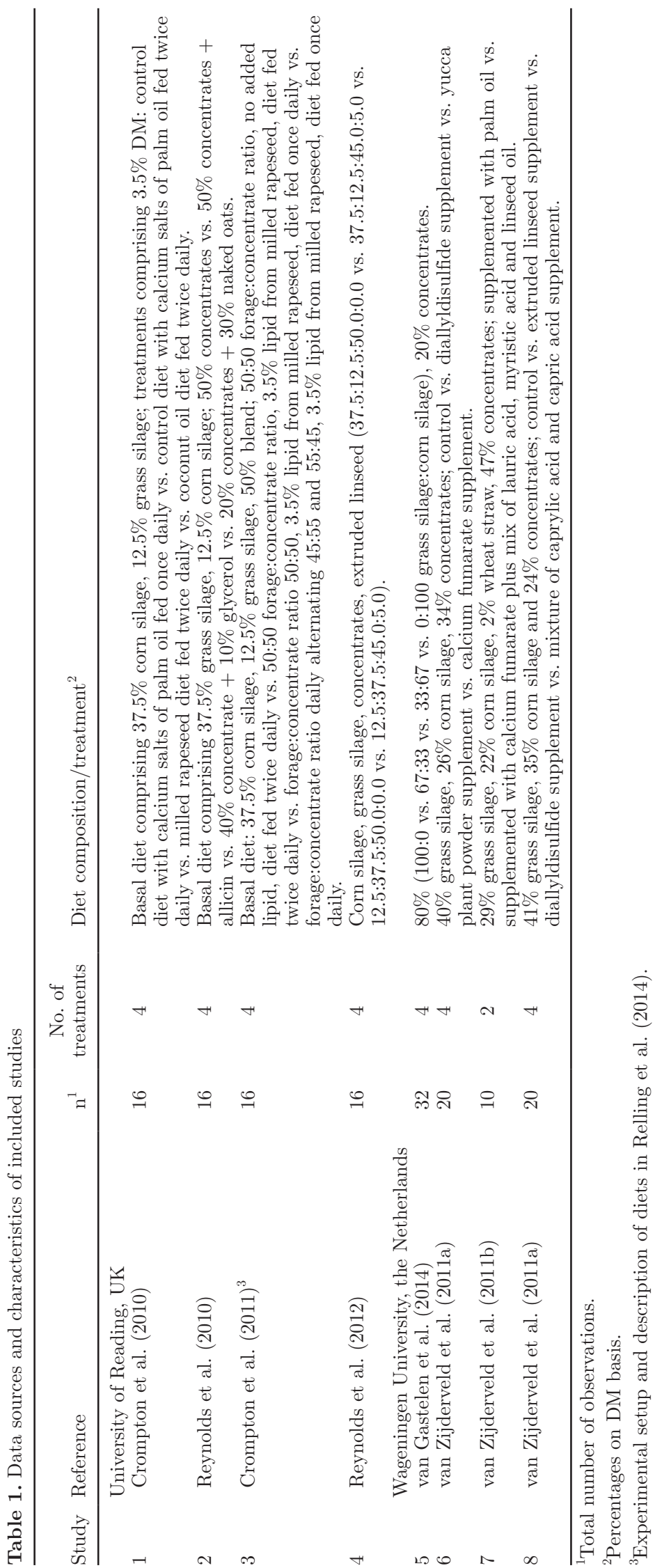


Table 2. Descriptive statistics of dietary and animal characteristics

\begin{tabular}{|c|c|c|c|c|}
\hline Variable & Mean & $\mathrm{SD}$ & Minimum & Maximum \\
\hline DMI $(\mathrm{kg} / \mathrm{d})$ & 18.5 & 2.41 & 13.1 & 26.1 \\
\hline $\mathrm{NDF}(\%$ of DM) & 37.0 & 3.76 & 29.0 & 42.2 \\
\hline $\mathrm{ADF}^{1}(\%$ of $\mathrm{DM})$ & 21.7 & 2.05 & 17.9 & 27.6 \\
\hline $\operatorname{Starch}^{2}(\%$ of DM $)$ & 16.5 & 6.39 & 0.42 & 25.7 \\
\hline Crude fat $^{3}$ ( $\%$ of DM) & 4.2 & 1.65 & 1.9 & 6.4 \\
\hline $\mathrm{CP}(\%$ of $\mathrm{DM})$ & 16.0 & 1.12 & 13.3 & 19.1 \\
\hline $\operatorname{Ash}(\%$ of $\mathrm{DM})$ & 7.3 & 0.92 & 5.0 & 9.4 \\
\hline Milk yield $(\mathrm{kg} / \mathrm{d})$ & 28.9 & 6.40 & 16.8 & 44.4 \\
\hline $\operatorname{FPCM}^{4}(\mathrm{~kg} / \mathrm{d})$ & 29.1 & 5.14 & 18.3 & 42.4 \\
\hline Milk fat $(\mathrm{g} / 100 \mathrm{~g}$ of milk $)$ & 4.20 & 0.679 & 2.28 & 6.24 \\
\hline Milk protein ( $\mathrm{g} / 100 \mathrm{~g}$ of milk) & 3.29 & 0.314 & 2.38 & 4.18 \\
\hline Milk lactose $(\mathrm{g} / 100 \mathrm{~g} \text { of milk })^{2}$ & 4.53 & 0.203 & 3.81 & 5.06 \\
\hline $\mathrm{CH}_{4}(\mathrm{~g} / \mathrm{d})$ & 395 & 51.2 & 250 & 508 \\
\hline $\mathrm{CH}_{4}(\mathrm{~g} / \mathrm{kg}$ of DMI $)$ & 21.5 & 2.46 & 15.9 & 27.9 \\
\hline $\mathrm{CH}_{4}(\mathrm{~g} / \mathrm{kg}$ of $\mathrm{FPCM})$ & 13.9 & 2.30 & 8.8 & 20.3 \\
\hline
\end{tabular}

${ }^{1}$ No data available for experiments 6,7 , and 8 .

${ }^{2}$ No data available for experiments 6 and 8 .

${ }^{3}$ No data available for experiment 4 .

${ }^{4}$ Fat- and protein-corrected milk.

these FA were individually identified in other studies, they were grouped together. Milk FA fractions were expressed in $\mathrm{g} / 100 \mathrm{~g}$ of total milk FA. Fatty acid fractions with an average study concentration $<0.1 \mathrm{~g} / 100 \mathrm{~g}$ of milk FA were excluded from the data set.

\section{Statistical Analysis}

Random-Effects Model Analysis. Relationships between $\mathrm{CH}_{4}$ yield per unit of feed and per unit of milk, and individual milk FA concentrations for dairy cattle were meta-analyzed using the metafor package (version 1.6-0; Viechtbauer, 2010) in R (version 2.15.2; R Foundation for Statistical Computing, Vienna, Austria). The effect size of these relationships for each of the 8 studies was estimated by correlation coefficients (values in Supplemental Tables S1 and S2; http:// dx.doi.org/10.3168/jds.2014-8268). The correlation coefficients were obtained by linear regression using individual animal data. In contrast to treatment mean

Table 3. Descriptive statistics of milk FA composition (g/100 g of total FA)

\begin{tabular}{|c|c|c|c|c|}
\hline Milk FA & Mean & SD & Minimum & Maximum \\
\hline $\mathrm{C} 4: 0$ & 3.18 & 0.46 & 1.44 & 4.32 \\
\hline C6:0 & 2.10 & 0.35 & 0.73 & 2.73 \\
\hline C8:0 & 1.19 & 0.22 & 0.51 & 1.61 \\
\hline C10:0 & 2.67 & 0.57 & 1.12 & 3.77 \\
\hline C12:0 & 3.29 & 1.13 & 1.50 & 10.70 \\
\hline C14:0-iso ${ }^{1}$ & 0.10 & 0.04 & 0.03 & 0.22 \\
\hline C14:0 & 11.18 & 1.79 & 6.82 & 18.24 \\
\hline cis-9 C14:1 & 1.05 & 0.35 & 0.57 & 3.23 \\
\hline C15:0-anteiso & 0.43 & 0.06 & 0.30 & 0.62 \\
\hline C15:0 & 0.99 & 0.25 & 0.64 & 2.25 \\
\hline C16:0-iso & 0.22 & 0.07 & 0.01 & 0.37 \\
\hline C16:0 & 31.28 & 4.91 & 19.91 & 42.29 \\
\hline $\mathrm{C} 17: 0$ & 0.55 & 0.12 & 0.27 & 0.82 \\
\hline C18:0 & 9.75 & 2.41 & 5.03 & 17.09 \\
\hline trans $-6+7+8+9 \mathrm{C} 18: 1^{2}$ & 0.57 & 0.32 & 0.25 & 1.63 \\
\hline trans-10+11 C18:1 & 1.46 & 1.01 & 0.51 & 9.00 \\
\hline cis-9 C18:1 $1^{3}$ & 19.31 & 3.67 & 12.32 & 29.80 \\
\hline cis-11 C18:1 $1^{2}$ & 0.60 & 0.21 & 0.30 & 1.37 \\
\hline cis-12 C18:1 & 0.28 & 0.13 & 0.07 & 0.81 \\
\hline cis-13 C18:1 & 0.17 & 0.11 & 0.04 & 0.65 \\
\hline trans $-16+$ cis-14 C18: $1^{2}$ & 0.33 & 0.19 & 0.10 & 0.90 \\
\hline cis-9,12 C18:2 & 1.54 & 0.37 & 0.57 & 2.94 \\
\hline cis- $9,12,15$ C18:3 & 0.45 & 0.17 & 0.14 & 1.02 \\
\hline C20:0 & 0.13 & 0.04 & 0.06 & 0.24 \\
\hline
\end{tabular}

${ }^{1}$ No data available from experiment 7 .

${ }^{2}$ No data available from experiment 5 .

${ }^{3}$ Co-eluted with trans-13+14-C18:1 in experiments 1 and 3; co-eluted with trans-12-C18:1 in experiment 5 . 
data, use of individual animal data prevents one from ignoring variation of $\mathrm{CH}_{4}$ production and milk $\mathrm{FA}$ concentrations at the animal level due to, for example, parity and DMI level. The correlation coefficients were transformed via Fisher's r-to-Z transformation, Z = $\tanh ^{-1}(\mathrm{r})$, where $\tanh ^{-1}=$ the inverse hyperbolic tangent, which is defined as follows: $\tanh ^{-1}(\mathrm{r})=0.5 \times$ $\ln [(1+r) /(1-r)]$ (Fisher, 1921). This transformation ensures more stable variance and normality. To obtain the average true effect, the meta-analytic model applied is given by

$$
y_{i}=\mu+u_{i}+e_{i}
$$

where $y_{i}$ is the observed effect in the $i$ th study, $\mu$ is the average true effect, $u_{i}$ is the variability among the true effect induced by study, and $e_{i}$ is the sampling error with $e_{i} \sim N\left(0, v_{i}\right)$. The sampling variance, $v_{i}$, is known based on the number of observations per study. The study effect, $u_{i}$, was taken into account as a random factor. This model is referred to as the random-effects model.

In the random-effects model, the variability among studies (or heterogeneity), which is regarded to be induced by experimental circumstances, is assumed to be normally distributed with variance $\tau^{2}$ such that $u_{i} \sim N\left(0, \tau^{2}\right)$. The model was fit with REML. Heterogeneity $\left(\tau^{2}\right)$ was expressed as percentage of the total variability in the effect size ( $\tau^{2}$ plus sampling error), yielding the $I^{2}$ statistic (Higgins et al., 2003). In case of negative values of $I^{2}$, a value of $0 \%$ was adopted; $I^{2}$ values greater than $50 \%$ indicate substantial heterogeneity. The transformed correlations were tested for homogeneity with the Q-statistic (Hedges and Olkin, 1985), which follows a $\chi^{2}$ distribution. Average true correlation coefficients and their boundaries of the $95 \%$ CI were back-transformed to raw correlation values for convenience of interpretation. Estimates of average true correlations were declared significant at $P \leq 0.05$ and tendencies at $0.05<P \leq 0.10$. The strength of the estimated average correlations is interpreted as small if $0.10 \leq|\mathrm{r}|<0.30$, medium if $0.30 \leq|\mathrm{r}|<0.50$, and large if $|\mathrm{r}| \geq 0.50$ (Cohen, 1988).

Mixed Model Regression Analysis. To predict the actual $\mathrm{CH}_{4}$ yield per unit of feed and per unit of milk, with milk FA concentrations as input, mixed model regression techniques (St-Pierre, 2001) were applied using PROC MIXED (SAS Institute Inc., Cary, NC). This enabled analysis of fixed effects of independent variables as well as the effect of study, which was taken into account as a random factor. The general model for single and multiple regression is represented as

$$
Y_{i j}=B_{0}+B_{1} X_{i j 1},+\ldots,+B_{k} X_{i j k}+s_{i}+e_{i j},
$$

where $Y_{i j}$ is the dependent variable (ith study $1, \ldots, 8$, $j$ th observation $1, \ldots, 146)$ and $X_{i j k}$ is the value of the $k$ th explanatory variable $(k=1,2, \ldots, p)$. The overall intercept $B_{0}$ and the overall regression coefficients of $Y$ on $X$ across all studies comprise the fixed-effects part of the model for $k$ different parameters. The random effect of the $i$ th study on the overall intercept $B_{0}, s_{i}$, together with the unexplained residual error, $e_{i j}$, comprise the random-effects part of the model, with both assumed to be normal. Random effects were modeled with (co) variance matrices that were fitted with an unstructured approach, providing that matrices converged. In cases of nonconvergence, (co)variance matrices were fitted with a compound symmetry. When matrices still did not converge, they were fitted with variance components. No random effect on slope was included in the multiple regression analysis to prevent overparameterization. A selection procedure for multiple regression was performed using a stepwise procedure (PROC GLMSELECT in SAS), retaining the experiment effect in every step, with $\mathrm{CH}_{4}$ yield being the dependent variable and stepwise selection of FA based on the Schwarz Bayesian information criterion, where lower values indicate better model adequacy. All available single FA or FA combinations were included in the selection. For predicting $\mathrm{CH}_{4}$ yield per unit of feed, milk fat and milk protein contents $(\mathrm{g} / 100 \mathrm{~g}$ of milk) were included in the selection as well. Parameter estimates for fixed effects were declared significant at $P \leq 0.05$. Adjusted dependent variable values were calculated based on regression parameters of the final model to determine $r$ or $\mathrm{R}^{2}$ values corrected for experiment effect (St-Pierre, 2001). The residuals (predicted minus observed) were visually inspected for any patterns, as well as for any potentially confounding factors.

\section{RESULTS AND DISCUSSION}

The studies used in this meta-analysis (see Table 1) comprised a notably larger variety of diets compared with Chilliard et al. (2009), Mohammed et al. (2011), and Dijkstra et al. (2011). In the present data set, the forage proportion varied between 50 and $80 \%$ of total diet, with forage consisting of grass silage and corn silage in ratios ranging from 0:100 to 100:0 (all on a DM basis). It remains questionable, though, to what extent the present data set represents the variety of diets supplied on commercial dairy farms. In particular, the large variation in forage proportion (fraction of total diet) and composition (type of forage and quality of forage) in practice is not completely represented in the 8 studies included. As in the previous analyses cited above, the data used in the present study include measurements for diets that include supplemental lip- 
ids and other ingredients with potential to reduce $\mathrm{CH}_{4}$ yield.

Study effect can be taken into account as either a fixed or random factor in meta-analysis and leads to a fixed-effects model or a random-effects model, respectively. In contrast to fixed-effects models that make a conditional inference only about the number of studies included in the analysis, random-effects models estimate the unconditional inference about a larger set of studies of which the studies included in the analysis are assumed to be a normally distributed random sample (Viechtbauer, 2010). Therefore, including the study effect as a random factor, not as fixed factor, is in better agreement with the aim of this meta-analysis to search for a generally applicable prediction equation for $\mathrm{CH}_{4}$ yield with milk FA concentration as input.

\section{Random-Effects Model Analysis Correlation per Unit of Feed}

The concentration of $\mathrm{C} 16: 0$ in milk fat was moderately positively related to $\mathrm{CH}_{4}$ yield $(\mathrm{g} / \mathrm{kg}$ of DMI), and concentrations of $\mathrm{C} 6: 0, \mathrm{C} 8: 0$, and $\mathrm{C} 10: 0$ in milk fat tended to be weakly positively related to $\mathrm{CH}_{4}$ yield (Table 4), which is largely in agreement with previous findings (Chilliard et al., 2009). These FA are synthesized de novo in the mammary gland from acetate and $\beta$-hydroxybutyrate produced in the rumen (Bernard et al., 2008). Ruminal acetate production is positively associated with fiber intake (Bannink et al., 2008), which subsequently yields $\mathrm{H}_{2}$ and ultimately $\mathrm{CH}_{4}$ by methanogenic archaea. Milk C4:0 concentration was not significantly related to $\mathrm{CH}_{4}$ yield. With the exception of $\mathrm{C} 4: 0$, de novo FA synthesis in the mammary gland of C16 and shorter FA is inhibited in the presence of unsaturated long-chain FA (Bernard et al., 2008; Shingfield et al., 2010). The fact that dietary unsaturated FA generally reduce $\mathrm{CH}_{4}$ yield may explain why concentrations of C4:0 were not related to $\mathrm{CH}_{4}$ yield, in contrast to other even-chain de novo synthesized FA. Moreover, C4:0 in milk fat does not require acetate for its production as it can be produced directly from $\beta$-hydroxybutyrate derived from the blood and thus only partly originates from de novo FA synthesis using acetate.

As for milk FA concentration of C4:0, no significant relationship was found between $\mathrm{CH}_{4}$ yield ( $\mathrm{g} / \mathrm{kg}$ of DMI) and concentrations of $\mathrm{C} 12: 0$ or C14:0. Based on genetic and herd clustering of milk FA, Heck et al. (2012) found that $\mathrm{C} 4: 0$ and $\mathrm{C} 12: 0$ differed from the general pattern of the other FA in the group of de novo synthesized even-chain FA. Milk FA C12:0 and C14:0 are not only synthesized de novo in the mammary gland, but can also originate from dietary $\mathrm{C} 12: 0$ and C14:0 (e.g., van Zijderveld et al., 2011b). Ingredients such as palm kernel expeller and extracted coconut, with relatively large proportions of C12:0 and C14:0 in fat, are commonly included in dairy cattle diets and were present in various diets in the current data set. Dietary C12:0 and $\mathrm{C} 14: 0$ inhibit $\mathrm{CH}_{4}$ production (Patra, 2013), which might explain why no overall correlation of concentrations $\mathrm{C} 12: 0$ and $\mathrm{C} 14: 0$ in milk fat and $\mathrm{CH}_{4}$ yield was found in this study. However, it should be noted that the level of either C12:0 or C14:0 fed was not available for most of the studies included in this meta-analysis. A part of $\mathrm{C} 14: 0$ is desaturated to cis-9 C14:1 by $\Delta^{9}$ desaturation in the mammary gland. This desaturation activity is regulated by genetics (Soyeurt et al., 2008) and may be stimulated by acetate from the rumen and inhibited by unsaturated FA from feed (Chilliard et al., 2007; Jacobs et al., 2011). These contrasting mechanisms together may result in milk cis-9 C14:1 not being related to $\mathrm{CH}_{4}$ yield in the present study. In contrast with our study, Chilliard et al. (2009) found milk FA concentrations of all even-chain de novo synthesized FA between $\mathrm{C} 4: 0$ and $\mathrm{C} 16: 0$ to be positively related to $\mathrm{CH}_{4}$ production. However, in the study of Chilliard et al. (2009), dietary treatments differed only in physical form of linseed.

Concentrations of OBCFA in milk FA are related to molar proportions of VFA in the rumen and have potential to be used as rumen microbial markers or indicators of the type of VFA formed and as predictors of $\mathrm{CH}_{4}$ yield (Vlaeminck et al., 2006a,b). Of the various OBCFA in milk fat in the present study, only C16:0-iso tended to be weakly positively related $(\mathrm{r}=0.22)$ with $\mathrm{CH}_{4}$ yield $(\mathrm{g} / \mathrm{kg}$ of DMI). This weak positive relationship is in line with Mohammed et al. (2011) and Castro Montoya et al. (2011), who attributed this to the fact that iso-FA are more abundant in cellulolytic bacteria (Vlaeminck et al., 2006a), which are associated with higher $\mathrm{CH}_{4}$ yield. Milk C14:0-iso concentration was positively related to $\mathrm{CH}_{4}$ yield in the study of Chilliard et al. (2009). An increased level of fiber in the diet generally results in increased $\mathrm{CH}_{4}$ yield and is associated with increased concentrations of C14:0-iso in milk fat (Boivin et al., 2013). This positive relationship was not confirmed in the current meta-analysis $(P=0.131)$. Vlaeminck et al. (2006a) reported negative and positive correlations of milk C15:0-anteiso concentration with NDF and starch, respectively. These 2 feed components have counteracting effects on $\mathrm{CH}_{4}$ yield (Ellis et al., 2008), which might explain why the concentration C15:0-anteiso in milk fat was not significantly related to $\mathrm{CH}_{4}$ yield in the present study. This result is in line with Fievez et al. (2012), who suggested that the concentration of C15:0-anteiso was relevant only in prediction of butyrate proportion in the rumen that is associated with dietary sugars (Oba, 2011). Elevated 
Table 4. Estimated true correlation coefficients with standard errors and $P$-values, $P$-values for heterogeneity test statistic $(\mathrm{Q}$-value $P$ ), and heterogeneity as a fraction of total variability $\left(I^{2}\right)$ for the correlation between $\mathrm{CH}_{4}$ yield per unit of feed and per unit of milk (fat- and proteincorrected milk, FPCM), and milk FA concentration

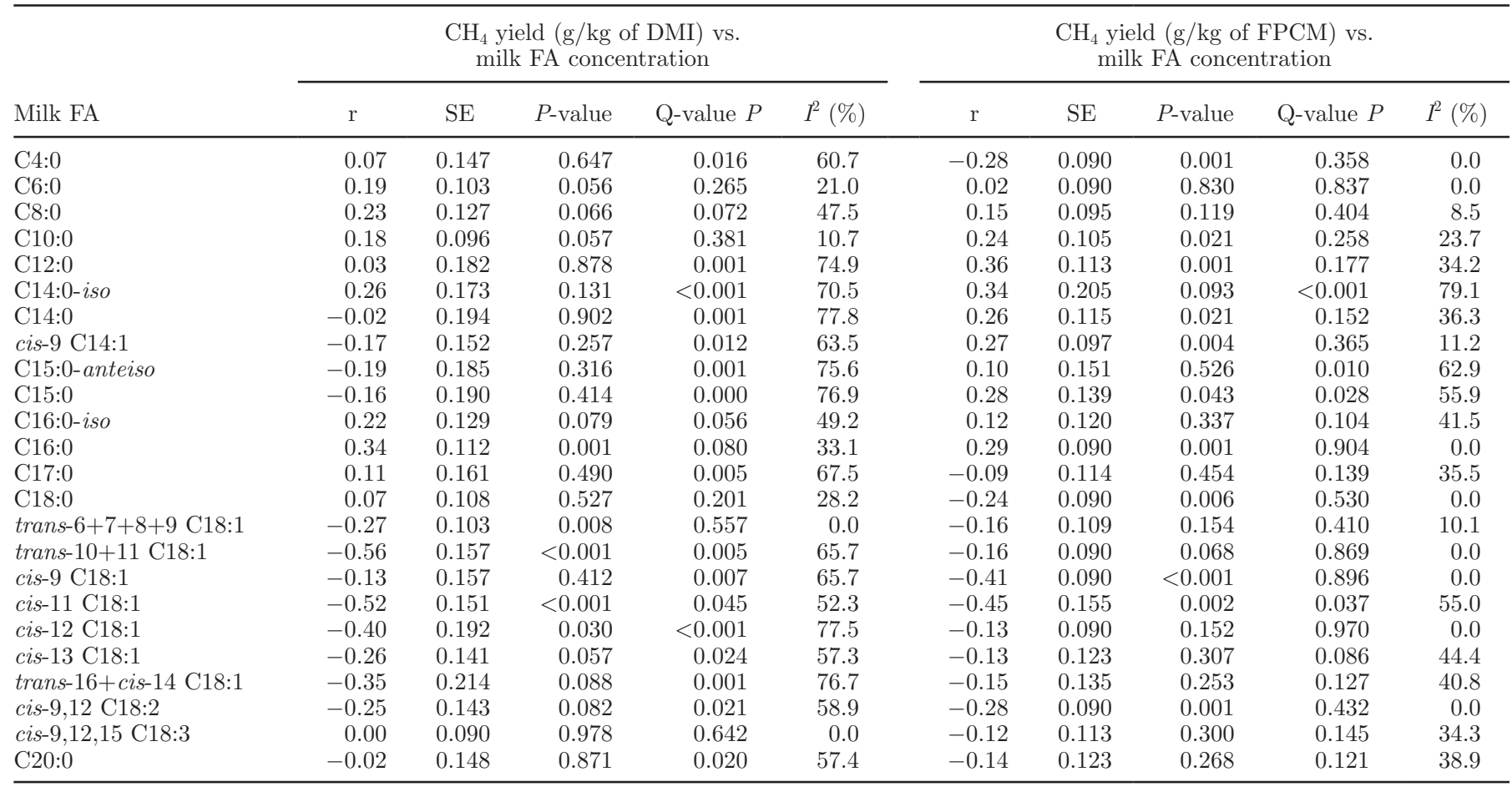

sugar contents may not increase $\mathrm{CH}_{4}$ yield (Staerfl et al., 2012) and may indicate that $\mathrm{CH}_{4}$ yield and milk C15:0-anteiso concentration are not related.

No significant relationships with $\mathrm{CH}_{4}$ yield $(\mathrm{g} / \mathrm{kg}$ of DMI) were found for concentrations of C15:0 and C17:0 in milk fat (Table 4). Two different hypotheses on the relationship between diet composition and these oddchain milk FA concentrations have been investigated. Patel et al. (2013) reported increased milk C15:0 concentration when feeding increased proportions of grass silage and dietary NDF levels, which was attributed to more abundant membrane lipids from rumen microbes. A high NDF content in the feed is associated with increased $\mathrm{CH}_{4}$ yield (Ellis et al., 2008). This indicates a positive relationship between odd-chain milk FA concentrations and $\mathrm{CH}_{4}$ yield. In contrast, Castro Montoya et al. (2011) reported milk concentrations of C15:0 and the sum of C17:0 and cis-9 C17:1 to be positively related to propionate concentration in the rumen as these are synthesized from propionate de novo (French et al., 2012). Propionate production is negatively related to $\mathrm{CH}_{4}$ production, suggesting a negative relationship between milk odd-chain FA concentration and $\mathrm{CH}_{4}$ yield. In the present meta-analysis, odd-chain FA concentrations in milk fat were not significantly related to $\mathrm{CH}_{4}$ yield. It should be noted that the concentration of cis-9 C17:1, a desaturation product of $\mathrm{C} 17: 0$ in the mammary gland, was not available in all experiments included in the present study. Grouping these 2 fractions together based on a broad database might shed new light on the relationship between $\mathrm{CH}_{4}$ yield and odd-chain FA concentration in milk, as also reported by Dijkstra et al. (2011), where the sum of milk FA concentrations C17:0 and cis-9 C17:1 was negatively related to $\mathrm{CH}_{4}$ yield. Overall, in line with Chilliard et al. (2009) and Mohammed et al. (2011), relationships between concentrations of OBCFA in milk and $\mathrm{CH}_{4}$ production were generally rather minor or absent, and also less than expected based on theoretical relationships between rumen fermentation products and $\mathrm{CH}_{4}$ yield (e.g., Vlaeminck et al., 2006a,b; Castro Montoya et al., 2011).

Several long-chain unsaturated FA in milk originate from dietary oils and their biohydrogenation products formed in the rumen. Higher concentrations of these FA in cattle diets, which are known to reduce DM and NDF digestibility, are negatively associated with $\mathrm{CH}_{4}$ yield (e.g., Patra, 2013). Milk cis-9,12 C18:2 and cis9,12,15 C18:3 directly originate from the corresponding FA in feed (Chilliard et al., 2007). Concentration of cis9,12 C18:2 in milk fat tended to be negatively related to $\mathrm{CH}_{4}$ yield $(\mathrm{g} / \mathrm{kg}$ of $\mathrm{DMI}), \mathrm{r}=-0.25$, in line with expectations. In general, replacing grass silage with corn silage reduces $\mathrm{CH}_{4}$ yield, and corn silage is rich 
in cis-9,12 C18:2 and increases the proportion of this FA in milk fat (Kliem et al., 2008). However, no relationship between milk cis-9,12,15 C18:3 concentration and $\mathrm{CH}_{4}$ yield was found in the present meta-analysis. Chilliard et al. (2007) stated that the potential to increase milk FA concentration cis-9,12,15 C18:3 was limited, with some positive effects upon feeding protected oilseed supplements in particular. Oilseeds in protected form may not decrease methanogenesis (Dohme et al., 2000) and may not result in a significant negative correlation between $\mathrm{CH}_{4}$ yield and milk cis-9,12,15 C18:3 concentration. The absence of a significant relationship between milk cis-9,12,15 C18:3 concentration and $\mathrm{CH}_{4}$ yield is in line with Chilliard et al. (2009) for diets that differ in type of linseed supplemented. Nonetheless, the study of Mohammed et al. (2011) included a linseed treatment, which is high in cis-9,12,15 C18:3, and indicated a moderate negative correlation between concentration of cis-9,12,15 C18:3 in milk fat and $\mathrm{CH}_{4}$ production $(\mathrm{g} / \mathrm{d})$. Additional evaluation of the rumen microbial metabolism of cis-9,12,15 C18:3 thus seems to be necessary to better understand these contrasting findings.

Various trans- and cis-C18:1 milk FA concentrations were negatively related to $\mathrm{CH}_{4}$ yield $(\mathrm{g} / \mathrm{kg}$ of DMI), as shown in Table 4. In general, trans-11 C18:1 is the major monounsaturated biohydrogenation intermediate of both cis-9,12,15 C18:3 and cis-9,12 C18:2 (e.g., Shingfield et al., 2010). These PUFA inhibit $\mathrm{CH}_{4}$ production, and milk trans-11 C18:1 concentration is therefore expected to be negatively related to $\mathrm{CH}_{4}$ yield. With reduced rumen $\mathrm{pH}$ values, the predominant biohydrogenation pathway of cis-9,12 C18:2 may shift to trans-10 C18:1 (Colman et al., 2012) and low rumen $\mathrm{pH}$ is negatively associated with $\mathrm{CH}_{4}$ production (Ellis et al., 2008). Besides, diets rich in unsaturated FA often cause a shift to trans-10 C18:1 formation (Mohammed et al., 2011) when $70 \%$ of the diet is roughage (Boeckaert et al., 2008). These observations explain the strong negative correlation $(\mathrm{r}=-0.56)$ obtained between milk trans-10+11 C18:1 concentration and $\mathrm{CH}_{4}$ yield. Like trans-10+11 C18:1, cis-11 C18:1 and cis-12 C18:1 and the fraction trans- $6+7+8+9 \mathrm{C} 18: 1$ result from biohydrogenation of both cis-9,12 C18:2 and cis-9,12,15 C18:3 (e.g., Jouany et al., 2007; Shingfield et al., 2010), and this explains their significantly negative strong $(\mathrm{r}=-0.53$; cis-11 C18:1), moderate $(\mathrm{r}=-0.40$; cis-12 C18:1), and weak $(\mathrm{r}=-0.27$; trans $-6+7+8+9$ C18:1) relationship of concentrations of these FA with $\mathrm{CH}_{4}$ yield.

Depending on their FA composition, different dietary lipids result in variable biohydrogenation products. Milk trans-16+cis-14 C18:1 concentration tended to be moderately negative related to $\mathrm{CH}_{4}$ yield $(\mathrm{r}=-0.35)$. Elevated levels of trans-16 C18:1 have been found in duodenal digesta (Glasser et al., 2008) and in milk (Kliem et al., 2009) upon supplementing diets with feed ingredients rich in cis-9,12,15 C18:3. trans-16+cis-14 C18:1 also appeared as an in vitro rumen biohydrogenation product of cis-9,12,15 C18:3 (Jouany et al., 2007), which might suggest that milk cis-14 C18:1 is derived from cis-9,12,15 C18:3. cis-13 C18:1 was increased in milk when increased contents of corn silage were fed (Kliem et al., 2008) and was increased in vitro when cis-9,12 C18:2 or cis-9,12,15 C18:3 were used as a substrate (Jouany et al., 2007). In this meta-analysis, the relationship tended to be weakly negative $(\mathrm{r}=$ -0.26 ) and may suggest that cis-13 $\mathrm{C} 18: 1$ is derived from both cis-9,12 C18:2 and cis-9,12,15 C18:3. The positive response of milk cis-13 C18:1 concentration to dietary linseed oil supplementation (Loor et al., 2004) further supports this.

Milk cis-9 C18:1 concentration was not significantly related to $\mathrm{CH}_{4}$ yield in the present meta-analysis. The absence of a significant relationship is in line with the analysis of Mohammed et al. (2011), whereas Chilliard et al. (2009) did find a significantly negative relationship. cis-9 C18:1, which inhibits $\mathrm{CH}_{4}$ production (e.g., Patra, 2013), is present in many feedstuffs and might be less sensitive to biohydrogenation than other unsaturated FA in high concentrate diets (Loor et al., 2004). Nonetheless, cis-9 C18:1 is converted into trans-C18:1 isomers in the rumen, possibly contributing to the negative correlations between concentrations of several milk trans-C18:1 isomers and $\mathrm{CH}_{4}$ yield as obtained in this study and discussed earlier (e.g., Shingfield et al. 2010). $\Delta^{9}$-Desaturation of C18:0 in the mammary gland is another mechanism by which cis-9 C18:1 appears in milk. Furthermore, dietary C18:0, being a possible substrate for $\Delta^{9}$-desaturase, was not observed to inhibit $\mathrm{CH}_{4}$ production (Patra, 2013), so does not contribute to a relation of milk cis-9 C18:1 and C18:0 concentrations with $\mathrm{CH}_{4}$ yield. In line with this and Mohammed et al. (2011), no relationship between milk C18:0 concentration and $\mathrm{CH}_{4}$ yield was found in this meta-analysis. This is in contrast with Chilliard et al. (2009), who found a negative relationship, possibly coming from dietary linoleic and linolenic acid, which were biohydrogenated to $\mathrm{C} 18: 0$ that was absorbed. Milk C20:0 is an elongation product by action of elongase enzymes on C18:0 from the diet or from body fat. The fact that milk C20:0 concentration and $\mathrm{CH}_{4}$ yield were not related in the present meta-analysis is in line with C18:0 concentration not being related overall to $\mathrm{CH}_{4}$ yield.

\section{Evaluation of Heterogeneity}

Milk C6:0, C8:0, C10:0, and C16:0 concentrations were not substantially heterogeneously correlated to 
$\mathrm{CH}_{4}$ yield per unit of feed (Table 4). These relatively low heterogeneities may indicate good precision of the estimated relationships and the simplicity of the mechanism determining the relationship. Next to de novo FA synthesis and feed, body fat is another source of milk C16:0 (Gross et al., 2011). Nonetheless, the de novo FA synthesis that regulates milk C16:0 concentration is positively associated with $\mathrm{CH}_{4}$ yield. Milk C16:0 from body fat and feed may not induce heterogeneity among the relationship. Unlike that of other saturated even-chain FA, milk C12:0 and C14:0 concentrations showed substantial heterogeneity among their true correlation with $\mathrm{CH}_{4}$ yield. Variation in diet composition, in particular when ingredients relatively rich in C12:0 and C14:0 are supplied to cattle (discussed in a previous section), may explain such heterogeneity. The sum of all de novo synthesized even-chain FA concentrations (C4:0 to C16:0, including $\mathrm{C} 12: 0$ and $\mathrm{C} 14: 0$ ) did not show any heterogeneity among its true correlation (Table 5).

The correlation of milk C14:0-iso, C15:0-anteiso, C15:0, C17:0 (Table 4), and of combined OBCFA concentrations; namely, C14:0-iso+C16:0-iso and C15:0+C17:0 (Table 5), were all substantially heterogeneous $\left(I^{2} \geq 61.1 \%\right)$. The heterogeneity observed for these milk OBCFA concentrations might reflect the variation in microbial species and activities in the rumen. All concentrations of individual C18:1 fractions appeared to be substantially heterogeneous $\left(I^{2}>50 \%\right)$, except for the trans- $6+7+8+9$ C18:1 fraction, which was totally homogeneous (Table 4). The combination of these 4 different FA may balance out all heterogeneity but does not indicate homogeneity for the correlation of the 4 individual FA concentrations. The correlation of the concentration of a combined fraction of milk cis- $11+12+13 \mathrm{C} 18: 1$ with $\mathrm{CH}_{4}$ yield was also homogeneous, even though substantial heterogeneity was observed using the individual milk FA concentrations (Table 5). Substantial heterogeneity was apparent for correlations between $\mathrm{CH}_{4}$ yield and concentrations of all combined fractions of $\mathrm{C} 18: 1$ isomers that contained trans-10+11 C18:1 and a tendency for heterogeneity when trans-16+cis-14 C18:1 was added to the fraction trans- $6+7+8+9$ C18:1 + cis- $11+12+13$ C18:1 (Table $5)$. Various concentrations of fractions with milk transC18:1 isomers and cis-9,12 C18:2 $\left(I^{2}=59.0 \%\right)$ did not, therefore, appear to be precise indicators of $\mathrm{CH}_{4}$ yield, whereas milk cis- $11+12+13 \mathrm{C} 18: 1$ and trans- $6+7+8+9$ C18:1 concentration did. The C18:1 isomers in milk other than isomers containing a cis-9 double bond mainly originate from the rumen, but microorganisms and enzymes responsible for their production are not well characterized, and candidate bacterial species have yet to be cultivated (Wallace et al., 2007; Lourenço et al., 2010). Isolation of bacterial species may help to better interpret heterogeneity and homogeneity observed.

\section{Random-Effects Model Analysis Correlation per Unit of Milk}

Positive relationships were obtained between $\mathrm{CH}_{4}$ yield $(\mathrm{g} / \mathrm{kg}$ of FPCM) and the milk FA concentrations of C10:0, C12:0, C14:0, cis-9 C14:1, C15:0, and C16:0. The concentration of $\mathrm{C} 14: 0-i s o$ tended to be

Table 5. Estimated true correlation coefficients with standard errors and $P$-values, $P$-values for heterogeneity test statistic $(\mathrm{Q}$-value $P)$, and heterogeneity as a fraction of total variability $\left(I^{2}\right)$ for the correlation between $\mathrm{CH}_{4}$ yield per unit of feed and milk FA concentration

\begin{tabular}{lrrrrr}
\hline Milk FA & \multicolumn{1}{c}{$\mathrm{r}$} & $\mathrm{SE}$ & $P$-value & Q-value $P$ & $I^{2}(\%)$ \\
\hline C6:0+C8:0+C10:0 & 0.22 & 0.11 & 0.050 & 0.173 & 34.0 \\
C6:0+C8:0+C10:0+C16:0 & 0.34 & 0.10 & $<0.001$ & 0.149 & 16.1 \\
C12:0+C14:0 & -0.02 & 0.20 & 0.919 & $<0.001$ & 79.4 \\
Even-chain C4:0 to C16:0 & 0.26 & 0.09 & 0.003 & 0.501 & 0.0 \\
C16:0+C18:0 & 0.42 & 0.09 & $<0.001$ & 0.128 & 5.6 \\
C15:0+C17:0 & -0.07 & 0.16 & 0.677 & 0.005 & 66.4 \\
C14:0-iso+C16:0-iso & 0.24 & 0.15 & 0.108 & 0.012 & 61.1 \\
trans-C18:1 $^{2}$ & -0.52 & 0.18 & $<0.001$ & 0.009 & 66.0 \\
cis-C18:1 $^{3} 18: 1^{4}$ & -0.52 & 0.10 & $<0.001$ & 0.570 & 0.0 \\
C18: $1^{5}$ & -0.56 & 0.16 & $<0.001$ & 0.003 & 68.5 \\
C18: $1^{6}$ & -0.49 & 0.14 & $<0.001$ & 0.079 & 42.1 \\
C18:2+C18:3 & -0.56 & 0.15 & $<0.001$ & 0.045 & 52.5 \\
\hline
\end{tabular}

${ }^{1}$ No data for experiment 7 .

${ }^{2}$ trans- $6+7+8+9+10+11-\mathrm{C} 18: 1$, no data for experiment 5 .

${ }^{3}$ cis-11+12+13-C18:1, no data for experiment 5 .

${ }^{4}$ trans-10+11-C18:1+cis-12+13-C18:1.

${ }^{5}$ trans $-6+7+8+9+16-\mathrm{C} 18: 1+$ cis- $11+12+13+14-\mathrm{C} 18: 1$, no data for experiment 5 .

${ }^{6}$ trans- $6+7+8+9+10+11+16-\mathrm{C} 18: 1+$ cis- $11+12+13+14-\mathrm{C} 18: 1$, no data for experiment 5 . 
positively related to $\mathrm{CH}_{4}$ yield. Negative relationships or a tendency for a negative relationship were obtained between $\mathrm{CH}_{4}$ yield and the milk FA concentration of C18:0, cis-9 C18:1, cis-11 C18:1, trans-10+11 C18:1, and cis-9,12 C18:2. These relationships and the absence of significant relationships between $\mathrm{CH}_{4}$ yield and milk FA concentrations of $\mathrm{C} 17: 0$, cis-9,12,15 C18:3, and C20:0 are largely in agreement with the correlations obtained when $\mathrm{CH}_{4}$ yield was expressed per unit of feed. In contrast to $\mathrm{CH}_{4}$ yield per unit of feed, no positive relationships were obtained between $\mathrm{CH}_{4}$ yield per unit of milk and milk FA concentration of C6:0 and C8:0, and a negative relationship was observed for the concentration of C4:0. Moreover, no significant relationship was obtained between the milk FA concentrations of trans- $6+7+8+9 \mathrm{C} 18: 1$, cis-12 C18:1, cis-13 C18:1, and trans-16+cis-14 $\mathrm{C} 18: 1$ and $\mathrm{CH}_{4}$ yield per unit of milk. This might be due to the fact that various biohydrogenation intermediates associated with a reduction in $\mathrm{CH}_{4}$ yield per unit feed (Table 4) are associated with milk fat depression (e.g., Piperova et al. 2000), which negatively affects the amount of FPCM, thus yielding more $\mathrm{CH}_{4}$ yield per unit of milk. A reduced correlation strength for trans-10+11 C18:1 per unit of feed and per unit of milk ( $\mathrm{r}=-0.56$ vs. $\mathrm{r}=-0.16$, respectively) is in line with this. The negative relationship between $\mathrm{CH}_{4}$ yield per unit of milk and the concentration of C18:0 in milk fat may be explained by the concentration of C18:0 being decreased during lactation (Stoop et al., 2009), when milk yield decreases and next $\mathrm{CH}_{4}$ yield per unit of milk increases. Milk FA concentration of the fraction odd-chain C5:0 to C15:0 and of cis-9 C18:1 are decreased and increased, respectively, during negative energy balance in early lactation (Stoop et al., 2009; Gross et al., 2011) when cows are producing at a high level. High milk production is associated with lower $\mathrm{CH}_{4}$ yield per unit of milk, which may explain why milk FA concentrations of C15:0 and cis-9 C18:1 were positively and negatively related to $\mathrm{CH}_{4}$ yield per unit of milk, as also shown by Chilliard et al. (2009). Concentrations of C15:0-anteiso and C16:0-iso in milk fat were not significantly related to $\mathrm{CH}_{4}$ yield per unit of milk, possibly because the proportion of branchedchain FA does not vary during lactation (Stoop et al., 2009).

Most of the milk FA that were significantly correlated, or tended to be correlated, with $\mathrm{CH}_{4}$ yield per unit of milk showed relatively low heterogeneity, with the exception of C14:0-iso, C15:0, and cis-11 C18:1 (Table 4). In general, milk FA concentrations may therefore be regarded as precise indicators of $\mathrm{CH}_{4}$ yield per unit of milk.

Correlations between $\mathrm{CH}_{4}$ yield $(\mathrm{g} / \mathrm{kg}$ of $\mathrm{FPCM}$ ) and combined milk FA concentrations were sig- nificantly positive for $\mathrm{C} 10: 0+\mathrm{C} 12: 0+\mathrm{C} 14: 0$, $\mathrm{C} 10: 0+\mathrm{C} 12: 0+\mathrm{C} 14: 0+\mathrm{C} 16: 0$, even-chain $\mathrm{C} 4: 0$ to $\mathrm{C} 16: 0$, and $\mathrm{C} 16: 0+\mathrm{C} 18: 0$, and were significantly negative or tended to be negative for the various combined fractions consisting of C18:1 isomers and for the sum of C18:2 and C18:3 (Table 6). The strongest positive and negative correlations were not stronger than those based on single FA fractions: 0.36 versus 0.36 for $\mathrm{C} 10: 0+\mathrm{C} 12: 0+\mathrm{C} 14: 0+\mathrm{C} 16: 0$ and $\mathrm{C} 12: 0$, and -0.43 versus -0.45 for trans- $10+11$ C18:1+cis-9+11 C18:1 and cis-11 C18:1, respectively. The fractions of evenchain saturated FA and C18:1 isomers were not or not substantially heterogeneously correlated. Concentrations of combined fractions of milk OBCFA; namely, $\mathrm{C} 15: 0+\mathrm{C} 17: 0$ and $\mathrm{C} 14: 0-i s o+\mathrm{C} 16: 0-i s o$, were not related to $\mathrm{CH}_{4}$ yield ( $\mathrm{g} / \mathrm{kg}$ of $\mathrm{FPCM}$ ), which is in line with the absence of such relationships of $\mathrm{CH}_{4}$ yield per unit feed. In general, most combined and single concentrations of milk FA showed less heterogeneity in the correlation with $\mathrm{CH}_{4}$ yield per unit of milk than with $\mathrm{CH}_{4}$ yield per unit of feed.

\section{Mixed Model Regression Analysis for $\mathrm{CH}_{4}$ Yield per Unit of Feed}

Mixed model fits to evaluate the potential to predict $\mathrm{CH}_{4}$ yield $(\mathrm{g} / \mathrm{kg}$ of DMI) using selected milk FA concentrations $\left(\mathrm{g} / 100 \mathrm{~g}\right.$ of $\mathrm{FA}$ ) resulted in $\mathrm{R}^{2}$ values of 0.15 and 0.17 for the concentration of milk C16:0 and the fraction C6:0+C8:0+10:0+C16:0, respectively (Figure 1). Thus, the concentration of the fraction $\mathrm{C} 6: 0+\mathrm{C} 8: 0+10: 0+\mathrm{C} 16: 0$ did not show a substantially stronger positive relationship with $\mathrm{CH}_{4}$ yield than the concentration of $\mathrm{C} 16: 0$ alone. The $\mathrm{R}^{2}$ values were $0.20,0.41,0.31$, and 0.41 for the prediction with milk FA concentrations of trans- $6+7+8+9$ C18:1, cis-11 C18:1, cis-11+12+13 C18:1, and C18:1 (trans $-6+7+8+9+10+11+16 \mathrm{C} 18: 1+$ cis- $11+12+13+14$ C18:1), respectively. Concentrations of C18:1 fractions that were grouped together did not result in a substantially stronger negative relationship with $\mathrm{CH}_{4}$ yield than concentrations of single C18:1 fractions.

The best multiple regression to predict $\mathrm{CH}_{4}$ yield using concentrations of milk FA is:

$$
\begin{gathered}
\mathrm{CH}_{4}(\mathrm{~g} / \mathrm{kg} \text { of } \mathrm{DMI})=23.39 \pm 1.21+9.74 \pm 3.23 \\
\times \mathrm{C} 16: 0-\text { iso }-1.06 \pm 0.17 \times \text { trans }-10+11 \mathrm{C} 18: 1 \\
-1.75 \pm 0.49 \times \text { cis }-9,12 \mathrm{C} 18: 2
\end{gathered}
$$

where milk FA concentrations are in $\mathrm{g} / 100 \mathrm{~g}$ of total FA, $\mathrm{R}^{2}=0.54$ after correction for experiment effect (StPierre, 2001), and $P \leq 0.003$ for all parameters. The 
Table 6. Estimated true correlation coefficients with standard errors and $P$-values, $P$-values for heterogeneity test statistic (Q-value $P$ ), and heterogeneity as a fraction of total variability $\left(I^{2}\right)$ for the correlation between $\mathrm{CH}_{4}$ yield per unit of milk and milk FA concentration

\begin{tabular}{|c|c|c|c|c|c|}
\hline Milk FA & $\mathrm{r}$ & $\mathrm{SE}$ & $P$-value & Q-value $P$ & $I^{2}(\%)$ \\
\hline $\mathrm{C} 6: 0+\mathrm{C} 8: 0$ & 0.08 & 0.090 & 0.384 & 0.753 & 0.0 \\
\hline $\mathrm{C} 10: 0+\mathrm{C} 12: 0+\mathrm{C} 14: 0$ & 0.30 & 0.112 & 0.006 & 0.182 & 33.1 \\
\hline $\mathrm{C} 10: 0+\mathrm{C} 12: 0+\mathrm{C} 14: 0+\mathrm{C} 16: 0$ & 0.36 & 0.090 & $<0.001$ & 0.982 & 0.0 \\
\hline Even-chain C4:0 to C16:0 & 0.34 & 0.090 & $<0.001$ & 0.979 & 0.0 \\
\hline $\mathrm{C} 16: 0+\mathrm{C} 18: 0$ & 0.23 & 0.090 & 0.010 & 0.794 & 0.0 \\
\hline $\mathrm{C} 15: 0+\mathrm{C} 17: 0$ & 0.23 & 0.154 & 0.128 & 0.009 & 64.3 \\
\hline $\mathrm{C} 14: 0-i s o+\mathrm{C} 16: 0-i s o^{1}$ & 0.22 & 0.183 & 0.233 & 0.002 & 73.6 \\
\hline $\operatorname{trans}-\mathrm{C} 18: 1^{2}$ & -0.17 & 0.103 & 0.092 & 0.720 & 0.0 \\
\hline cis-C18: $1^{3}$ & -0.41 & 0.103 & $<0.001$ & 0.809 & 0.0 \\
\hline $\mathrm{C} 18: 1^{4}$ & -0.43 & 0.090 & $<0.001$ & 0.864 & 0.0 \\
\hline $\mathrm{C} 18: 1^{5}$ & -0.43 & 0.103 & $<0.001$ & 0.735 & 0.0 \\
\hline $\mathrm{C} 18: 1^{6}$ & -0.42 & 0.103 & $<0.001$ & 0.734 & 0.0 \\
\hline $\mathrm{C} 18: 2+\mathrm{C} 18: 3$ & -0.24 & 0.090 & 0.007 & 0.516 & 0.0 \\
\hline
\end{tabular}

${ }^{1}$ No data for experiment 7 .

${ }^{2}$ trans $-6+7+8+9+10+11 \mathrm{C} 18: 1$, no data for experiment 5 .

${ }^{3}$ cis- $9+11+12+13 \mathrm{C} 18: 1$, no data for experiment 5 .

${ }^{4}$ trans- $10+11 \mathrm{C} 18: 1+$ cis- $9+12+13 \mathrm{C} 18: 1$.

${ }^{5}$ trans- $10+11 \mathrm{C} 18: 1+$ cis-9+11 C18:1, no data for experiment 5 .

${ }^{6}$ trans $-6+7+8+9+10+11+16 \mathrm{C} 18: 1+$ cis $-9+11+12+13+14 \mathrm{C} 18: 1$, no data for experiment 5 .

model acceptably reproduced the $\mathrm{CH}_{4}$ yield (Figure 2), as the slope and intercept of the regression between observed and predicted values did not differ from 1 and 0 , respectively (results not shown). No clear patterns appear in the observed versus predicted values of $\mathrm{CH}_{4}$ yield and residual versus predicted values of $\mathrm{CH}_{4}$ yield (Figure 3), which does not indicate substantial bias or heteroscedasticity. The obtained $\mathrm{R}^{2}$ was larger than for concentrations of single milk FA fractions but lower than the value (0.73) that Dijkstra et al. (2011) obtained for their equation based on 3 experiments, and also lower than 0.82 (single experiment; Mohammed et al., 2011; only FA concentrations included in prediction equation) and 0.95 (single experiment; Chilliard et al., 2009; milk FA concentration and forage intake in prediction equation). The data used by Dijkstra et al. (2011) are also included in the present analysis. The larger number of studies included in our meta-analysis, including a wider variety of diet compositions, may have resulted in the lower $\mathrm{R}^{2}$ value of Equation [3]. A similar issue may hold when comparing the multiple regression analysis of Dijkstra et al. (2011) with the analyses of Mohammed et al. (2011), based on diets supplemented with sunflower seed, linseed, and canola seed, and Chilliard et al. (2009), based on linseed supplements only. On the other hand, Dijkstra et al. (2011) did not include forage intake in their equation and expressed $\mathrm{CH}_{4}$ yield in grams per kilogram of DMI, whereas Chilliard et al. (2009) and Mohammed et al. (2011) expressed $\mathrm{CH}_{4}$ production in grams per day. Furthermore, the substantial heterogeneity of the correlation of $\mathrm{CH}_{4}$ yield and milk FA concentrations of several C18:1 isomers found in the present analysis may limit a precise prediction of $\mathrm{CH}_{4}$ yield ( $\mathrm{g} / \mathrm{kg}$ of DMI) using milk FA profile.

Equation [3] of the present meta-analysis has various milk FA concentrations in common with previously reported equations. Milk C16:0-iso concentration did appear in the best equation of Mohammed et al. (2011). Milk trans-10+11 C18:1 concentration was also included by Dijkstra et al. (2011), and Mohammed et al. (2011) included all trans-C18:1 FA concentrations in their second-best equation based on milk FA concentrations and DMI. Milk cis-9,12 C18:2 concentrations was also present in the best equation of Chilliard et al. (2009). However, milk cis-9,12 C18:2 concentration was positively related to $\mathrm{CH}_{4}$ in that equation, whereas it was negatively related in Equation [3] of the current meta-analysis.

Different FA concentrations available for selection in different studies may hamper the development of a universally valid $\mathrm{CH}_{4}$ prediction equation based on milk FA concentrations. A stepwise selection was performed for concentrations of all milk FA that were available in 7 experiments to extend the number of available FA with C14:0-iso, trans-6+7+8+9 C18:1, cis-11 C18:1, and trans-16+cis-14 C18:1. Methane yield was best predicted by the concentration of C16:0-iso (positively related) and the concentrations of cis-11 C18:1 and trans-16+cis-14 C18:1 (both negatively related), with $P \leq 0.02$ for all regressors and $\mathrm{R}^{2}=0.55$. The concentration of cis-11 C18:1 was also present in the equation of Dijkstra et al. (2011) and in the second-best equation of Mohammed et al. (2011), and trans-16+cis-14 C18:1 concentration also appeared in the best and second- 

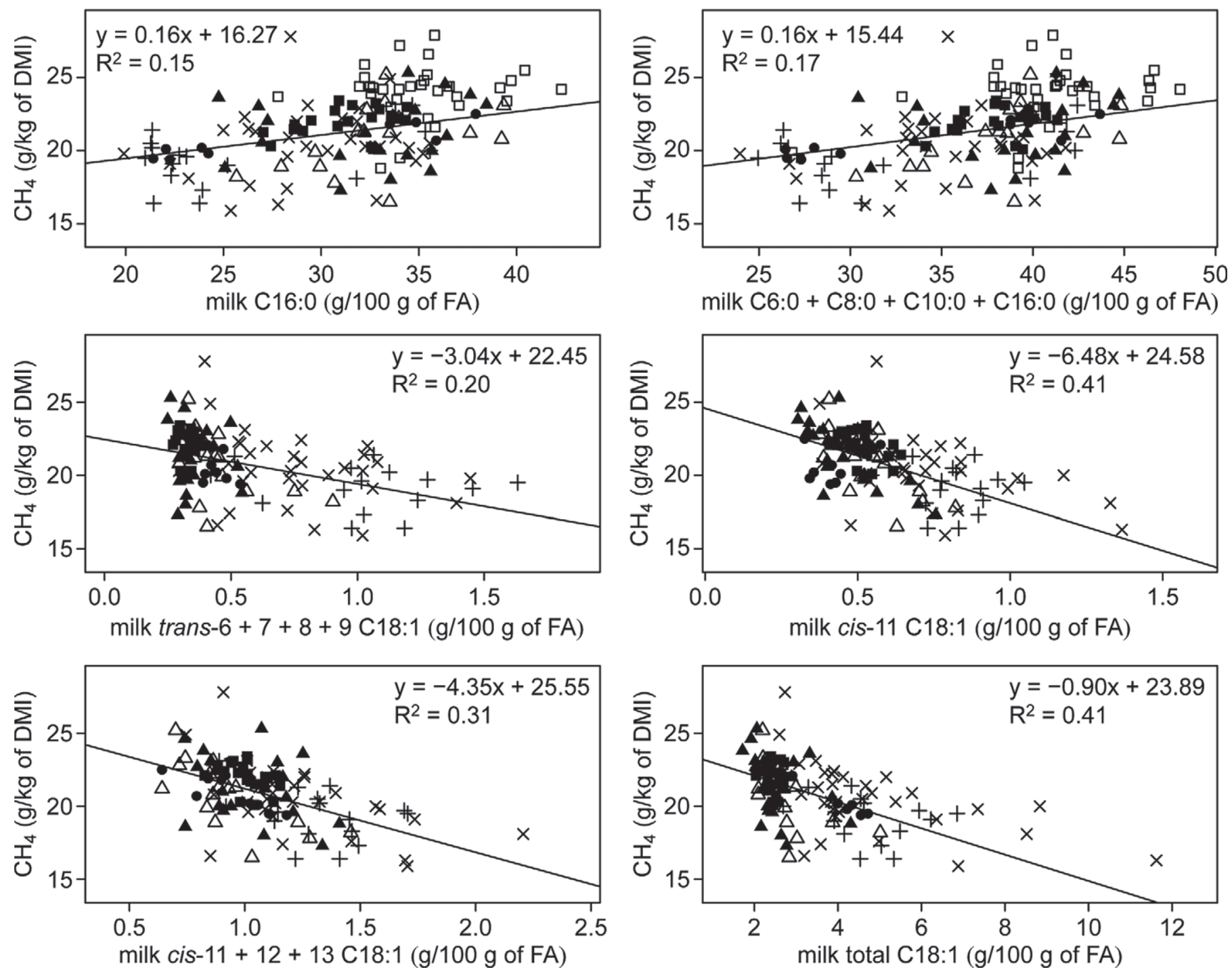

Figure 1. Relationships between $\mathrm{CH}_{4}$ yield $(\mathrm{g} / \mathrm{kg}$ of DMI) and selected milk FA concentrations. Milk total $\mathrm{C} 18: 1$ comprises trans-6+7+8+9 C18:1, trans-10+11 C18:1, cis-11 C18:1, cis-12 C18:1, cis-13 C18:1, and trans-16+cis-14 C18:1 for experiments 1 to 4 and 6 to 8. The different symbols identify the 8 individual experiments described in Table 1 (see Figure 2 for explanation).

best equations of Chilliard et al. (2009). However, the equation based on 7 experiments with $\mathrm{R}^{2}=0.55$ is not preferred over Equation [3] because it is based on one less experiment and the coefficient of determination is just marginally higher. Total milk fat and milk protein content were never selected and might illustrate the value of concentrations of single milk FA to predict $\mathrm{CH}_{4}$ yield.

In addition to gas chromatography, Fourier transform infrared spectroscopy (FTIR) is often applied to quantify FA concentrations in milk. To achieve a reasonable accuracy of milk FA concentrations with FTIR, FA should have an average concentration of $\geq 2.45 \mathrm{~g} / 100 \mathrm{~g}$ of FA (Rutten et al., 2009). Restricting the selection of milk FA with this threshold concentration would have resulted in a best equation based on positive relationships of concentrations of $\mathrm{C} 14: 0, \mathrm{C} 16: 0$, and $\mathrm{C} 18: 0$ and $\mathrm{R}^{2}=0.29$. More recently, Soyeurt et al. (2011) found concentrations of milk C4:0, C6:0, C8:0, C10:0, C12:0, C14:0, C16:0, C18:0, all trans-C18:1, cis-9 C18:1, all cis-C18:1, and some groups of FA in milk to be sufficiently accurately determined by FTIR to be used in milk payment systems. Including these FA concentrations mentioned by Soyeurt et al. (2011) in a selection procedure resulted in a best equation with a negative relationship of all trans-C18:1 concentration, where it is noted that the trans-C18:1 fraction consisted of all trans-C18:1 available in studies 1 to 4 and 6 to 8 . The $\mathrm{R}^{2}$ value was 0.43 for this equation, lower than that obtained for Equation [3]. Several milk FA with lower 


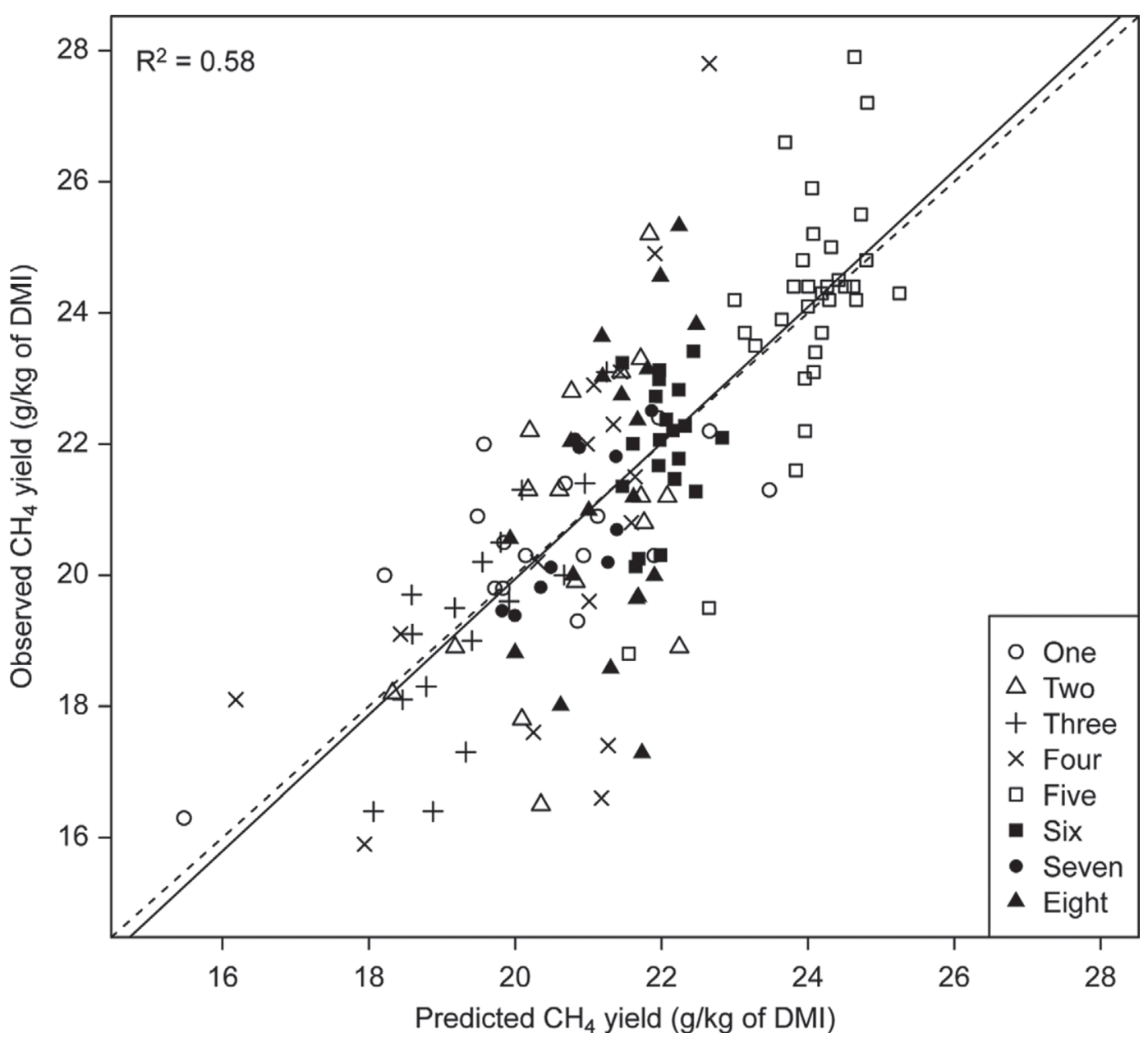

Figure 2. Observed versus predicted $\mathrm{CH}_{4}$ yield per unit of feed from Equation [3], including experiment as a discrete class variable with experiment effect not shown. The different symbols identify the 8 individual experiments. The line of unit slope represents the line of equivalence.

concentrations that appear in various equations published previously are not available when milk FA profile is determined using FTIR. Furthermore, concentrations of combined FA fractions, several of which are accurately determined with FTIR, did not substantially increase the potential for predicting $\mathrm{CH}_{4}$ yield (Figure 1). Compared with gas chromatography, the current performance of FTIR therefore limits the potential for predicting $\mathrm{CH}_{4}$ yield based on milk FA profile.

\section{Mixed Model Regression Analysis for $\mathrm{CH}_{4}$ Yield per Unit of Milk}

The best multiple regression to predict $\mathrm{CH}_{4}$ yield using concentrations of milk FA was as follows:

$$
\begin{aligned}
& \mathrm{CH}_{4}(\mathrm{~g} / \mathrm{kg} \text { of } \mathrm{FPCM})=21.13 \pm 1.72-1.38 \pm 0.38 \\
& \times \mathrm{C} 4: 0+8.53 \pm 3.05 \times \mathrm{C} 16: 0-\text { iso }-0.22 \pm 0.04 \\
& \times \text { cis-9 } \mathrm{C} 18: 1-0.59 \pm 0.18 \times \text { trans- } 10+11 \mathrm{C} 18: 1, \quad \text {, }
\end{aligned}
$$

where $\mathrm{R}^{2}=0.47$ after correction for experiment effect (St-Pierre, 2001) and $P \leq 0.006$ for all parameters. The model acceptably reproduced the $\mathrm{CH}_{4}$ yield (Figure 4), as the slope and intercept of the regression between observed and predicted values did not differ from 1 and 0 , respectively (results not shown). No clear patterns appear in the observed versus predicted values of $\mathrm{CH}_{4}$ yield and residual versus predicted values of $\mathrm{CH}_{4}$ yield (Figure 5), which does not indicate substantial bias or heteroscedasticity. The obtained $\mathrm{R}^{2}$ value was somewhat smaller than that for the prediction of $\mathrm{CH}_{4}$ yield per unit of feed. Equation [4] also contains milk C16:0-iso and trans-10+11 C18:1 concentration (like Equation [3]) to predict $\mathrm{CH}_{4}$ yield per unit of feed. Therefore, this may be regarded as further evidence for concentrations of milk C16:0-iso and trans-10+11 C18:1 being appropriate predictors of $\mathrm{CH}_{4}$ yield.

Restricting the selection of milk FA with a threshold concentration of $2.45 \mathrm{~g} / 100 \mathrm{~g}$ of FA for reasonable accuracy using FTIR would have resulted in a best 


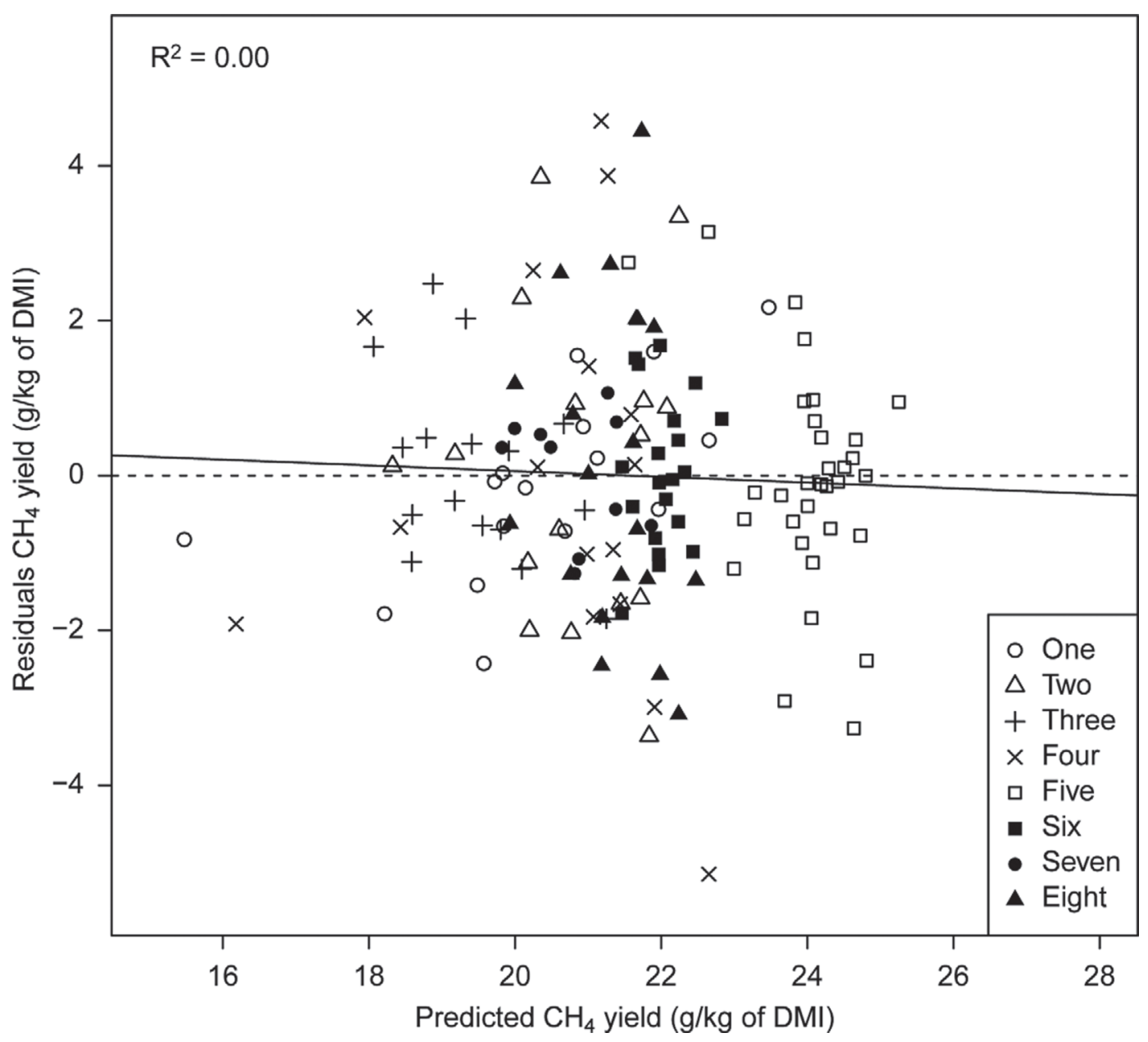

Figure 3. Residuals (predicted minus observed) and predicted $\mathrm{CH}_{4}$ yield per unit of feed from Equation [3], including experiment as a discrete class variable with experiment effect not shown. The different symbols identify the 8 individual experiments.

prediction equation based on negative relationships of concentrations of $\mathrm{C} 4: 0$ and cis-9 $\mathrm{C} 18: 1$, and $\mathrm{R}^{2}$ $=0.28$. Including the FA concentrations mentioned by Soyeurt et al. (2011) in the selection procedure resulted in a best equation based on negative relationships of concentrations of $\mathrm{C} 4: 0$, cis-9 $\mathrm{C} 18: 1$, and total trans-C18:1, and $\mathrm{R}^{2}=0.36$. It is noted that all $\mathrm{FA}$ available in studies 1 to 4 and 6 to 8 were included in the selection procedure because trans-10+11 C18:1 is the only trans-C18:1 fraction available in all 8 studies. Similar to prediction of $\mathrm{CH}_{4}$ yield per unit feed, these results indicate that current performance of FTIR limits the potential for predicting $\mathrm{CH}_{4}$ yield per unit of milk based on milk FA profile, compared with gas chromatography.

The present meta-analysis showed that milk FA profile has moderate potential to predict $\mathrm{CH}_{4}$ yield. Further improvement in ability of milk FA-based models to predict $\mathrm{CH}_{4}$ yield may be achieved by distinguishing diets with or without lipid supplements and by including diet composition characteristics. The present data set was too small to allow separate analyses of lipidsupplemented and non-lipid-supplemented diets, and more data may be required to analyze possible effects of lipid supplements on the relationship. On diet composition, Mohammed et al. (2011) already indicated that the combination of milk FA profile and diet characteristics may improve prediction performance. For practical application, this requires knowledge of diet composition (including forage to concentrate ratio and chemical composition of feed consumed), which may not always be available.

\section{CONCLUSIONS}

Various FA concentrations in milk fat appeared to be weakly, moderately, or strongly related to $\mathrm{CH}_{4}$ yield per unit of feed. Milk C6:0, C8:0, C10:0, C16:0, 


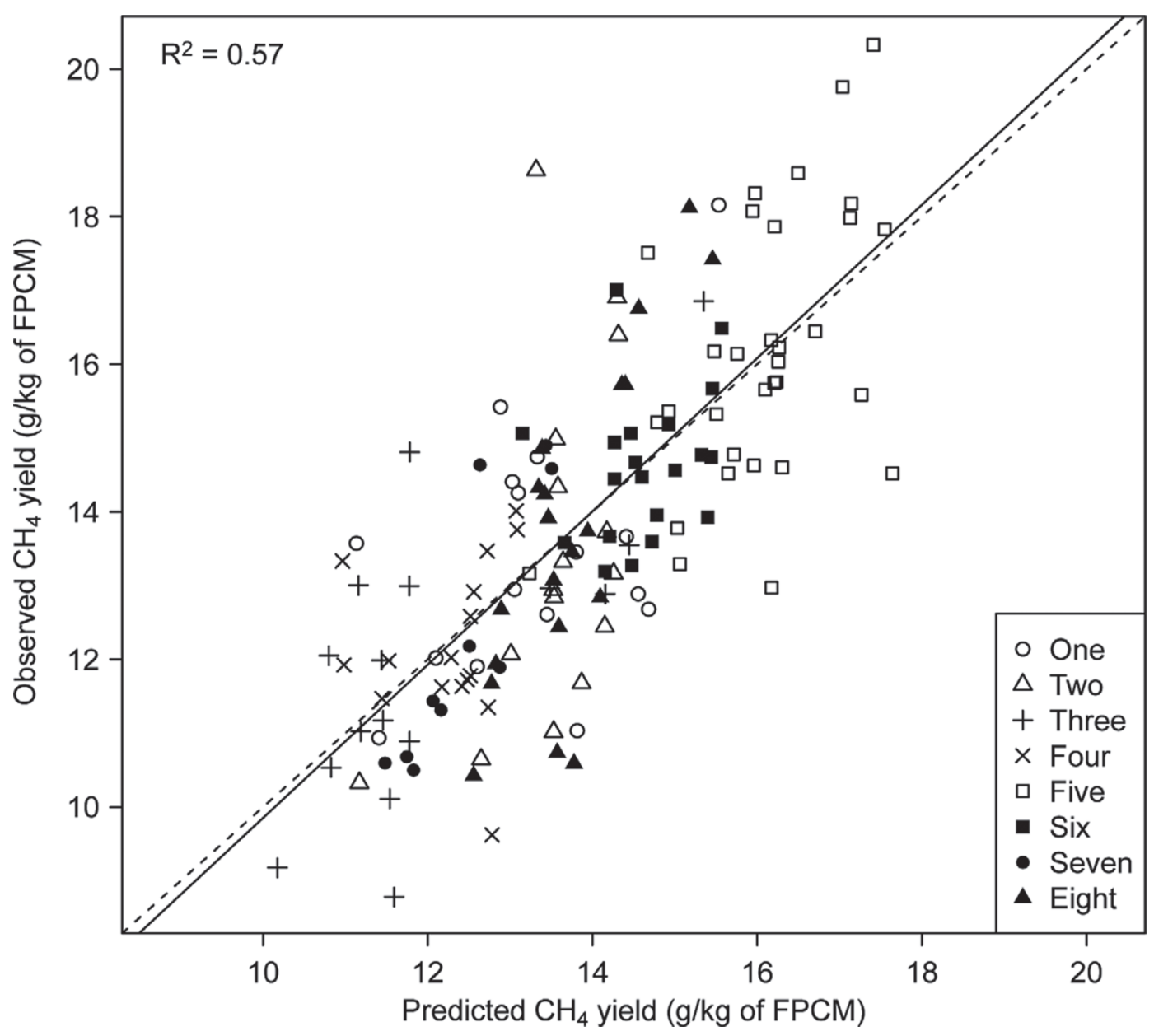

Figure 4. Observed versus predicted $\mathrm{CH}_{4}$ yield per unit of milk (fat- and protein-corrected milk yield, FPCM) from Equation [4], including experiment as a discrete class variable with experiment effect not shown. The different symbols identify the 8 individual experiments. The line of unit slope represents the line of equivalence.

and C16:0-iso concentrations showed positive relationships, whereas milk cis-9,12 C18:2, trans-10+11 $\mathrm{C} 18: 1$, cis-11 C18:1, cis-12 C18:1, cis-13 C18:1, and trans-16+cis-14 C18:1 concentrations showed weak to strong negative relationships with $\mathrm{CH}_{4}$ yield. Milk OBCFA concentrations C14:0-iso, C15:0-anteiso, C15:0, and C17:0, as well as milk C4:0, C12:0, C14:0, cis-9 C14:1, C18:0, cis-9 C18:1, cis-9,12,15 C18:3, and $\mathrm{C} 20: 0$ concentrations were not significantly related to $\mathrm{CH}_{4}$ yield per unit of feed. When expressing $\mathrm{CH}_{4}$ yield per unit of milk, relationships of milk C10:0, C15:0-anteiso, C16:0, C17:0, trans-10+11 C18:1, cis11 C18:1, cis-9,12 C18:2, cis-9,12,15 C18:3, and C20:0 concentrations were in line with relationships expressing $\mathrm{CH}_{4}$ yield per unit of feed. Concentrations of C18:1 isomers in milk fat showed more heterogeneity among the true correlation with $\mathrm{CH}_{4}$ yield per unit of feed than concentrations of the saturated even-chain FA
C6:0, C8:0, C10:0, and C16:0. Mixed model multiple regression resulted in various milk FA included in optimal equations to predict $\mathrm{CH}_{4}$ yield per unit of feed and per unit of milk, with C16:0-iso and trans-10+11 C18:1 concentrations appearing in both equations. These regressions indicated moderate potential for using milk FA profile to predict $\mathrm{CH}_{4}$ yield per unit of feed and per unit of milk.

\section{ACKNOWLEDGMENTS}

The financial support of UK Defra projects LS3656 and AC0209 and Marks and Spencer (London, UK) is gratefully acknowledged for studies at the University of Reading. Authors acknowledge financial support of SenterNovem, an agency of the Dutch Ministry of Economic Affairs, to obtain part of the data on DMI, milk production, and $\mathrm{CH}_{4}$ production. 


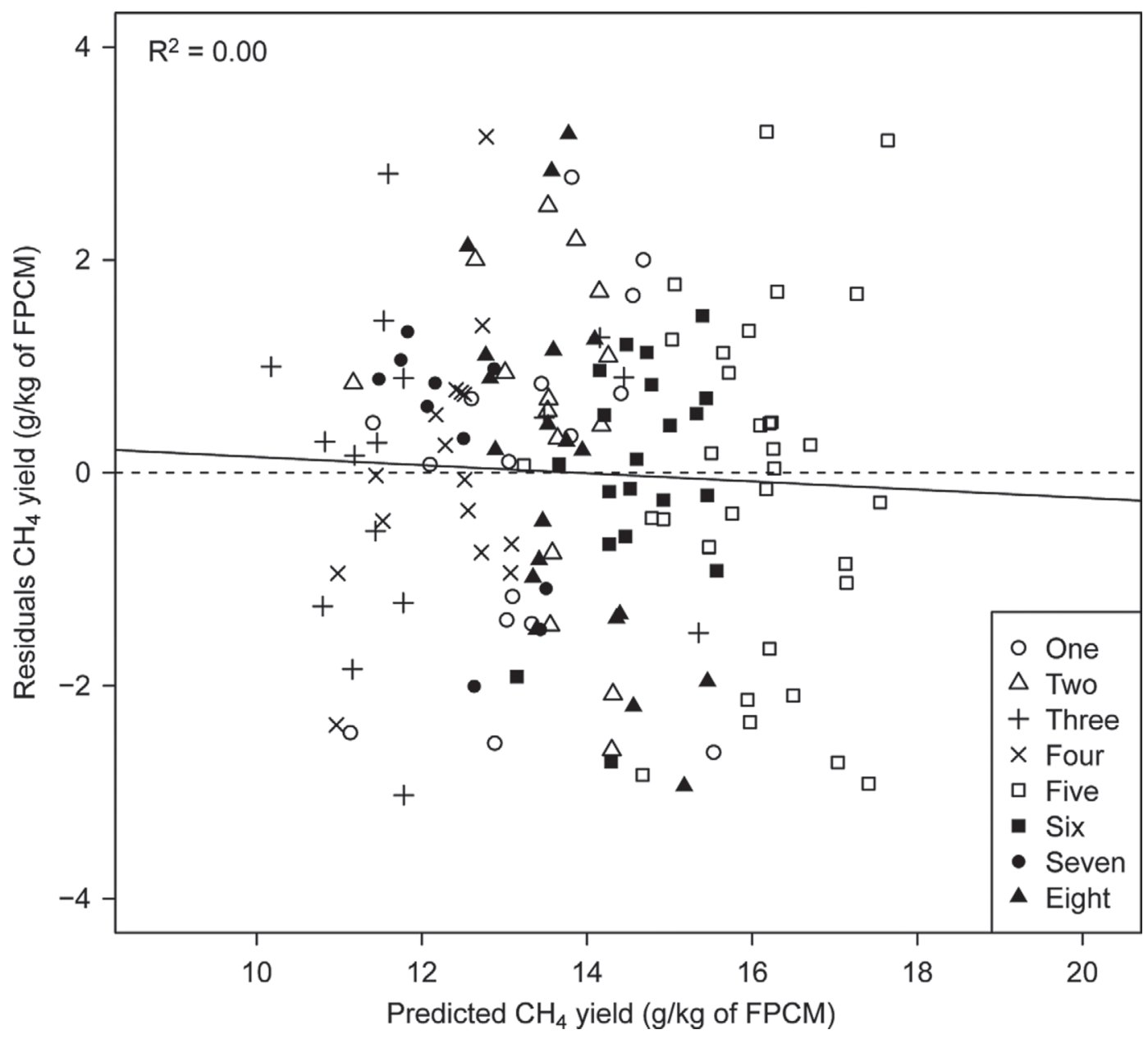

Figure 5. Residuals (predicted minus observed) and predicted $\mathrm{CH}_{4}$ yield per unit of milk (fat- and protein-corrected milk yield, FPCM) from Equation [4], including experiment as a discrete class variable with experiment effect not shown. The different symbols identify the 8 individual experiments.

\section{REFERENCES}

Alemu, A. W., J. Dijkstra, A. Bannink, J. France, and E. Kebreab. 2011. Rumen stoichiometric models and their contribution and challenges in predicting enteric methane production. Anim. Feed Sci. Technol. 166:761-778.

Bannink, A., J. France, S. Lopez, W. J. J. Gerrits, E. Kebreab, S. Tamminga, and J. Dijkstra. 2008. Modelling the implications of feeding strategy on rumen fermentation and functioning of the rumen wall. Anim. Feed Sci. Technol. 143:3-26.

Bernard, L., C. Leroux, and Y. Chilliard. 2008. Expression and nutritional regulation of lipogenic genes in the ruminant lactating mammary gland. Adv. Exp. Med. Biol. 606:67-108.

Boeckaert, C., B. Vlaeminck, J. Dijkstra, A. Issa-Zacharia, T. van Nespen, W. van Straalen, and V. Fievez. 2008. Effect of dietary starch or micro algae supplementation on rumen fermentation and milk fatty acid composition of dairy cows. J. Dairy Sci. 91:47144727.

Boivin, M., R. Gervais, and P. Y. Chouinard. 2013. Effect of grain and forage fractions of corn silage on milk production and composition in dairy cows. Animal 7:245-254.

Castro Montoya, J., A. M. Bhagwat, N. Peiren, S. De Campeneere, B. De Baets, and V. Fievez. 2011. Relationships between odd- and branched-chain fatty acid profiles in milk and calculated enteric methane proportion for lactating dairy cattle. Anim. Feed Sci. Technol. 166:596-602.

Chilliard, Y., F. Glasser, A. Ferlay, L. Bernard, M. Rouel, and J Doreau. 2007. Diet, rumen biohydrogenation and nutritional quality of cow and goat milk fat. Eur. J. Lipid Sci. Technol. 109:828855.

Chilliard, Y., C. Martin, J. Rouel, and M. Doreau. 2009. Milk fatty acids in dairy cows fed whole crude linseed, extruded linseed, or linseed oil, and their relationship with methane output. J. Dairy Sci. 92:5199-5211.

Cohen, J. 1988. Statistical Power Analysis for the Behavioral Sciences. 2nd ed. Lawrence Erlbaum Associates, Mahwah, NJ.

Colman, E., B. M. Tas, W. Waegeman, B. De Baets, and V. Fievez. 2012. The logistic curve as a tool to describe the daily ruminal $\mathrm{pH}$ pattern and its link with milk fatty acids. J. Dairy Sci. 95:58455865 .

Crompton, L. A., J. A. N. Mills, K. E. Kliem, and C. K. Reynolds. 2011. Effect of milled rapeseed on methane emissions and milk quality in lactating dairy cows. Adv. Anim. Biosci. 2:75.

Crompton, L. A., J. A. N. Mills, and C. K. Reynolds. 2010. Effect of feeding frequency and replacing calcium salts of palm oil with crushed rapeseed or coconut oil on methane emissions in lactating dairy cows. Proc. Nutr. Soc. 69:E329. 
CVB. 2008. CVB Table Booklet Feeding of Ruminants. CVB series no. 43. Centraal Veevoederbureau, Lelystad, the Netherlands.

Dijkstra, J., S. M. van Zijderveld, J. A. Apajalahti, A. Bannink, W. J. J. Gerrits, J. R. Newbold, H. B. Perdok, and H. Berends. 2011. Relationships between methane production and milk fatty acid profiles in dairy cattle. Anim. Feed Sci. Technol. 166:590-595.

Dohme, F., A. Machmüller, A. Wasserfallen, and M. Kreuzer. 2000. Comparative efficiency of various fats rich in medium-chain fatty acids to suppress ruminal methanogenesis as measured with RUSITEC. Can. J. Anim. Sci. 80:473-484.

Ellis, J. L., A. Bannink, J. France, E. Kebreab, and J. Dijkstra. 2010. Evaluation of enteric methane prediction equations for dairy cows used in whole farm models. Glob. Change Biol. 16:3246-3256.

Ellis, J. L., J. Dijkstra, E. Kebreab, A. Bannink, N. E. Odongo, B. W. McBride, and J. France. 2008. Aspects of rumen microbiology central to mechanistic modelling of methane production in cattle. J. Agric. Sci. 146:213-233.

Fievez, V., E. Colman, J. M. Castro-Montoya, I. Stefanov, and B. Vlaeminck. 2012. Milk odd- and branched-chain fatty acids as biomarkers of rumen function-An update. Anim. Feed Sci. Technol. 172:51-65.

Fisher, R. A. 1921. On the "probable error" of a coefficient of correlation deduced from a small sample. Metron 1:1-32.

French, E. A., S. J. Bertics, and L. E. Armentano. 2012. Rumen and milk odd- and branched-chain fatty acid proportions are minimally influenced by ruminal volatile fatty acid infusions. J. Dairy Sci. 95:2015-2026.

Gerber, P. J., H. Steinfeld, B. Henderson, A. Mottet, C. Opio, J. Dijkman, A. Falcucci, and G. Tempio. 2013. Tackling Climate Change Through Livestock-A Global Assessment of Emissions and Mitigation Opportunities. Food and Agriculture Organization of the United Nations (FAO), Rome, Italy.

Glasser, F., P. Schmidely, D. Sauvant, and M. Doreau. 2008. Digestion of fatty acids in ruminants: A meta-analysis of flows and variation factors: 2. C18 fatty acids. Animal 2:691-704.

Gross, J., H. A. van Dorland, R. M. Bruckmaier, and F. J. Schwarz. 2011. Milk fatty acid profile related to energy balance in dairy cows. J. Dairy Res. 78:479-488.

Heck, J. M. L., H. J. van Valenberg, H. Bovenhuis, J. Dijkstra, and T. C. van Hooijdonk. 2012. Characterization of milk fatty acids based on genetic and herd parameters. J. Dairy Res. 79:39-46.

Hedges, L. V., and I. Olkin. 1985. Statistical Methods for Meta-Analysis. Academic Press, San Diego, CA.

Higgins, J. P. T., S. G. Thompson, J. J. Deeks, and D. G. Altman. 2003. Measuring inconsistency in meta-analyses. BMJ 327:557560.

Hristov, A. N., J. Oh, J. L. Firkins, J. Dijkstra, E. Kebreab, G. Waghorn, H. P. S. Makkar, A. T. Adesogan, W. Yang, C. Lee, P. J. Gerber, B. Henderson, and J. M. Tricarico. 2013. Mitigation of methane and nitrous oxide emissions from animal operations: I. A review of enteric methane mitigation options. J. Anim. Sci. 91:5045-5069.

Jacobs, A. A. A., J. van Baal, M. A. Smits, H. Z. H. Taweel, W. H. Hendriks, A. M. van Vuuren, and J. Dijkstra. 2011. Effects of feeding rapeseed oil, soybean oil, or linseed oil on stearoyl-CoA desaturase expression in the mammary gland of dairy cows. J. Dairy Sci. 94:874-887.

Jouany, J. P., B. Lassalas, M. Doreau, and F. Glasser. 2007. Dynamic features of the rumen metabolism of linoleic acid, linolenic acid and linseed oil measured in vitro. Lipids 42:351-360.

Kliem, K. E., P. C. Aikman, D. J. Humphries, R. Morgan, K. J. Shingfield, and D. I. Givens. 2009. Effect of replacing calcium salts of palm oil distillate with extruded linseeds on milk fatty acid composition in Jersey and Holstein cows. Animal 3:1754-1762.

Kliem, K. E., R. Morgan, D. J. Humphries, K. J. Shingfield, and D. I. Givens. 2008. Effect of replacing grass silage with maize silage in the diet on bovine milk fatty acid composition. Animal $2: 1850-1858$.

Loor, J. J., K. Ueda, A. Ferlay, Y. Chilliard, and M. Doreau. 2004. Biohydrogenation, duodenal flow, and intestinal digestibility of trans fatty acids and conjugated linoleic acids in response to di- etary forage: Concentrate ratio and linseed oil in dairy cows. J. Dairy Sci. 87:2472-2485.

Lourenço, M., E. Ramos-Morales, and R. J. Wallace. 2010. The role of microbes in rumen lipolysis and biohydrogenation and their manipulation. Animal 4:1008-1023.

Mohammed, R., S. M. McGinn, and K. A. Beauchemin. 2011. Prediction of enteric methane output from milk fatty acid concentrations and rumen fermentation parameters in dairy cows fed sunflower, flax, or canola seeds. J. Dairy Sci. 94:6057-6068.

Oba, M. 2011. Review: Effects of feeding sugars on productivity of lactating dairy cows. Can. J. Anim. Sci. 91:37-46.

Patel, M., E. Wredle, and J. Bertilsson. 2013. Effect of dietary proportion of grass silage on milk fat with emphasis on odd- and branched-chain fatty acids in dairy cows. J. Dairy Sci. 96:390-397.

Patra, A. K. 2013. The effect of dietary fats on methane emissions, and its other effects on digestibility, rumen fermentation and lactation performance in cattle: A meta-analysis. Livest. Sci. 155:244-254.

Piperova, L. S., B. B. Teter, I. Bruckental, J. Sampugna, S. E. Mills, M. P. Yurawecz, J. Fritsche, K. Ku, and R. A. Erdman. 2000. Mammary lipogenic enzyme activity, trans fatty acids and conjugated linoleic acids are altered in lactating dairy cows fed a milk fat-depressing diet. J. Nutr. 130:2568-2574.

Relling, A. E., L. A. Crompton, S. C. Loerch, and C. K. Reynolds. 2014. Short communication: Plasma concentration of glucosedependent insulinotropic polypeptide may regulate milk energy production in lactating dairy cows. J. Dairy Sci. 97:2440-2443.

Reynolds, C. K., D. J. Humphries, P. Kirton, L. A. Crompton, J. A. N. Mills, and D. I. Givens. 2010. Methane production by lactating dairy cows fed diets containing allicin, glycerol or naked oats. Page 120 in Proc. 4th Intl. Greenhouse Gases Anim. Agric. Conf., Banff, Canada.

Reynolds, C. K., D. J. Humphries, P. Kirton, M. Kindermann, S. Duval, and W. Steinberg. 2014. Effects of 3-nitrooxypropanol on methane emission, digestion, and energy and nitrogen balance of lactating dairy cows. J. Dairy Sci. 97:3777-3789.

Reynolds, C. K., D. J. Humphries, K. M. Livingstone, K. E. Kliem, and D. I. Givens. 2012. Effect of forage type and an extruded linseed supplement on methane production by lactating dairy cows. Adv. Anim. Biosci. 3:9.

Rutten, M. J. M., H. Bovenhuis, K. A. Hettinga, H. J. F. van Valenberg, and J. A. M. van Arendonk. 2009. Predicting bovine milk fat composition using infrared spectroscopy based on milk samples collected in winter and summer. J. Dairy Sci. 92:6202-6209.

Shingfield, K. J., L. Bernard, C. Leroux, and Y. Chilliard. 2010. Role of trans fatty acids in the nutritional regulation of mammary lipogenesis in ruminants. Animal 4:1140-1166.

Soyeurt, H., F. Dehareng, N. Gengler, S. McParland, E. Wall, D. P. Berry, M. Coffey, and P. Dardenne. 2011. Mid-infrared prediction of bovine milk fatty acids across multiple breeds, production systems, and countries. J. Dairy Sci. 94:1657-1667.

Soyeurt, H., F. Dehareng, P. Mayeres, C. Bertozzi, and N. Gengler. 2008. Variation of $\Delta^{9}$-desaturase activity in dairy cattle. J. Dairy Sci. 91:3211-3224.

Spek, J. W., J. Dijkstra, G. van Duinkerken, and A. Bannink. 2013. A review of factors influencing milk urea concentration and its relationship with urinary urea excretion in lactating dairy cattle. J. Agric. Sci. 151:407-423.

St-Pierre, N. R. 2001. Invited review: Integrating quantitative findings from multiple studies using mixed model methodology. J. Dairy Sci. 84:741-755.

Staerfl, S. M., S. L. Amelchanka, T. Kälber, C. R. Soliva, M. Kreuzer, and J. O. Zeitz. 2012. Effect of feeding dried high-sugar ryegrass ('AberMagic') on methane and urinary nitrogen emissions of primiparous cows. Livest. Sci. 150:293-301.

Stoop, W. M., H. Bovenhuis, J. M. L. Heck, and J. A. M. van Arendonk. 2009. Effect of lactation stage and energy status on milk fat composition of Holstein-Friesian cows. J. Dairy Sci. 92:1469-1478.

Storm, I. M. L. D., A. L. F. Hellwing, N. I. Nielsen, and J. Madsen. 2012. Methods for measuring and estimating methane emission from ruminants. Animal 2:160-183. 
van Gastelen, S., E. C. Antunes Fernandes, K. A. Hettinga, G. Klop, S. J. J. Alferink, and J. Dijkstra. 2014. Replacing grass silage with maize silage affects rumen fermentation characteristics and enteric methane production in dairy cattle. In Proc. 39th Anim. Nutr. Res. Forum, Utrecht, the Netherlands. Universiteit Utrecht, Utrecht, the Netherlands.

van Knegsel, A. T. M., H. van den Brand, J. Dijkstra, W. M. van Straalen, M. J. W. Heetkamp, S. Tamminga, and B. Kemp. 2007. Dietary energy source in dairy cows in early lactation: energy partitioning and milk composition. J. Dairy Sci. 90:1467-1476.

van Zijderveld, S. M., J. Dijkstra, H. B. Perdok, J. R. Newbold, and W. J. J. Gerrits. 2011a. Dietary inclusion of diallyl disulfide, yucca powder, calcium fumarate, an extruded linseed product, or medium-chain fatty acids does not affect methane production in lactating dairy cows. J. Dairy Sci. 94:3094-3104.

van Zijderveld, S. M., B. Fonken, J. Dijkstra, W. J. J. Gerrits, H. B. Perdok, W. Fokkink, and J. R. Newbold. 2011b. Effects of a combination of feed additives on methane production, diet digestibility, and animal performance in lactating dairy cows. J. Dairy Sci. 94:1445-1454.

Viechtbauer, W. 2010. Conducting meta-analyses in R with the metafor package. J. Stat. Softw. 36:1-48.

Vlaeminck, B., V. Fievez, A. R. J. Cabrita, A. J. M. Fonseca, and R. J. Dewhurst. 2006a. Factors affecting odd- and branched-chain fatty acids in milk: A review. Anim. Feed Sci. Technol. 131:389-417.

Vlaeminck, B., V. Fievez, S. Tamminga, R. J. Dewhurst, A. van Vuuren, D. de Brabander, and D. Demeyer. 2006b. Milk odd- and branched-chain fatty acids in relation to the rumen fermentation pattern. J. Dairy Sci. 89:3954-3964.

Wallace, R. J., N. McKain, K. J. Shingfield, and E. Devillard. 2007. Isomers of conjugated linoleic acids are synthesized via different mechanisms in ruminal digesta and bacteria. J. Lipid Res. $48: 2247-2254$. 